Running head: UNEXPECTED AND JUST MISSED

\author{
Unexpected and Just Missed: The Separate Influence of the \\ Appraisals of Expectancy and Proximity on Negative Emotions \\ Evelien Bossuyt, Agnes Moors, and Jan De Houwer \\ Ghent University
}

Author Note

Evelien Bossuyt, Agnes Moors, and Jan De Houwer, Department of Experimental Clinical and Health Psychology, Ghent University.

Preparation of this paper was supported by a Ph.D. fellowship of the Scientific Research Foundation, Flanders (FWO), Belgium, to Evelien Bossuyt, FWO Research Project G.0223.13, and Methusalem Grant BOF09/01M00209 of Ghent University. We would like to thank Elke Godefroid for assistance with the experiment.

Please address correspondence to Evelien Bossuyt, Ghent University, Faculty of Psychology and Educational Sciences, Department of Experimental Clinical and Health Psychology, Henri Dunantlaan 2, 9000 Ghent, Belgium. Email: Evelien.Bossuyt@Ugent.be 


\begin{abstract}
Previous research suggested that a goal-incongruent outcome leads to more intense negative emotions when it is unexpected and close to a goal-congruent outcome. Until now, however, no studies have disentangled the influence of the appraisals of expectancy and proximity on emotions. We experimentally manipulated each of these variables in three slot machine experiments and measured emotions via differences in motivation (i.e., the tendency to repair the goal incongruence) and feelings (i.e., disappointment, frustration, and anger). The experiments consisted of a series of trials that each started with the sequential presentation of three symbols. In case of a win trial, all symbols were equal (e.g., AAA) and the participant gained ten cents; in case of a loss trial, one or more of the symbols were different and the participant gained zero cents. Three different loss trials were compared: unexpected proximal ones (e.g., AAB), expected proximal ones (e.g., ABA), and expected distal ones (e.g., ABC). The tendency to repair was measured online via behavior as well as retrospectively via self-reports; feelings were measured retrospectively (Experiments 1 and 2) or online (Experiment 3). Unexpected losses seemed to increase the tendency to repair as well as feelings of disappointment (in all experiments) and feelings of frustration and anger (in Experiments 1 and 3). Proximal losses increased only the tendency to repair (in all experiments). This suggests that the appraisals of expectancy and proximity have a distinct influence on emotions.
\end{abstract}

Keywords: Motivation, Expectancy, Disappointment, Frustration, Repair 


\section{Unexpected and Just Missed: The Separate Influence of the Appraisals of Expectancy and Proximity on Negative Emotions.}

Life is filled with opportunities, maybes, and pities: the political candidate that was ahead in the exit polls but eventually loses the elections by a couple of votes, the tennis champion that plays the final of her favorite tournament but loses the last set in a tie break, the audience of Romeo and Juliet that anticipates a happy ending, but ends up watching Romeo commit suicide a few seconds before Juliet wakes up from an induced coma. Negative outcomes seem to induce much more intense and long-lasting emotions when a positive outcome was highly anticipated and just missed than when a positive outcome was never anticipated and missed by far. To date, it remains unclear whether the expectation of a positive outcome and the perception that it was just missed (i.e., proximity) both influence emotions or whether one of the two dictates the emotion. We present two studies in which we experimentally tease apart expectancy and proximity to investigate their influence on negative emotions.

As in most contemporary emotion research, we adopt a componential view of emotions. This view states that emotions have various components: (a) a cognitive component consisting of an appraisal of the situation, (b) a motivational component consisting of changes in action readiness and specific action tendencies, (c) a somatic component consisting of (neuro)physiological changes, (d) a motor component consisting of expressive and gross behavior, and (e) a feeling or experience component (Moors, 2009; Scherer, 2005). In addition, we adopt the assumption of appraisal theories that not the stimulus itself, but the appraisal of the stimulus determines the content of the (other) componential changes (Arnold, 1960; Frijda, 1986). Appraisal is a process that evaluates the significance of a stimulus for well-being (Frijda, 1986; Scherer, 2001; Smith \& Lazarus, 1990). Appraisal theories propose that stimuli are 
appraised on a number of variables, such as goal relevance, goal congruence, coping potential, agency, and expectancy (Frijda, 1986; Lazarus, 1991; Roseman, Antoniou, \& Jose, 1996; Scherer, 1988). Goal relevance refers to the extent to which a stimulus touches on the person's goals or concerns. Goal congruence refers to the degree to which a stimulus matches with these goals (values: goal incongruent vs. goal congruent). Coping potential refers to the potential that a person has to turn a goal-incongruent stimulus in a goal-congruent one (low vs. high coping potential). Agency refers to the cause of the stimulus (values: self, other, circumstances). Expectancy refers to the degree to which a stimulus matches with the person's expectations (values: expected vs. unexpected). Proximity is not mentioned in existing appraisal theories, yet the idea that it plays a role in emotion elicitation and/or differentiation is compatible with an appraisal view and could be incorporated in these theories. Proximity is short for causal proximity (Kahneman \& Varey, 1990) and is used to describe the number of elements of the causal sequence of the current stimulus that is shared with the causal sequence of an alternative (here, goal-congruent) stimulus. In case many elements are shared (proximal outcome), one can say that the alternative almost happened; in case few elements are shared (distal outcome), one can say that the alternative was far from happening.

Appraisal theorists further propose that the output of the appraisal process directly drives the action tendencies that prepare the organism to respond to its environment (Frijda, Kuipers, \& ter Schure, 1989; Scherer, 1994). This preparation process has (neuro)physiological correlates, such as an increase in heart rate and activity in motor cortices, and can elicit actual behavioral changes (Frijda, et al., 1989; Scherer, 1994). A feeling or emotional experience arises when the appraisal, action tendencies, physiology, and behavior are reflected in consciousness (Grandjean, Sander, \& Scherer, 2008). 
We investigated the influence of the appraisals of expectancy and proximity on the motivational and the feeling components. Several emotion researchers predict that the appraisal of expectancy has an influence on emotions (e.g., Fraisse, 1964; Reisenzein, 2009; Roseman, 2011). In the literature on counterfactual thinking (Kahneman \& Miller, 1986; Kahneman \& Tversky, 1982; Medvec \& Savitsky, 1997), however, the idea is prevalent that proximity influences emotions. Our first aim was to examine whether a stimulus appraised as goal incongruent elicits different motivations and feelings when it is also appraised as expected vs. unexpected, while controlling for the appraisal of proximity. Our second aim was to investigate whether a stimulus appraised as goal incongruent elicits different motivations and feelings when it is also appraised as proximal vs. distal to a goal-congruent stimulus, while controlling for the appraisal of expectancy. Our third aim was to directly compare the influence of the appraisals of expectancy and proximity. Following construal level theory, one could predict that both expectancy and proximity influence emotional responding. Construal level theory builds on the literature on counterfactual thinking and suggests that emotions depend not only on the immediate situation, but also on mental construals of alternative situations (Trope \& Liberman, 2010). Moreover, this theory proposes that the intensity of the emotional response depends on the psychological distance between the current situation and its construed alternative. Among other things, the psychological distance depends on the probability of an alternative (Trope \& Liberman, 2010). Expectancy and proximity both relate to the probability of an alternative: If an obtained outcome (e.g., a loss) is appraised as unexpected, this implies that at an earlier point in time the probability of an alternative (e.g., a win) was estimated as high; if an obtained outcome is appraised as proximal to an alternative, it implies that after obtaining the outcome, one retrospectively estimates that the probability of obtaining the alternative was high. Thus, both 
appraisals of expectancy and proximity relate to the psychological distance to the goal-congruent outcome and each may influence the emotional response.

There is a bulk of research that investigates the influence of the appraisals of either expectancy or proximity on motivations and/or feelings, but these studies often fail to control (experimentally or statistically) for the other variable. Moreover, there is virtually no research that compares the influence of both variables. The next sections describe a handful of these studies organized according to the component of emotion (motivational or feeling) that was examined.

\section{The Motivational Component}

Previous research suggests that a goal-incongruent stimulus that is appraised as unexpected and proximal to a goal-congruent stimulus elicits more active behavior, more problem-solving behavior, and more risk-taking behavior. Most existing studies, however, do not allow isolating the effects of expectancy and/or proximity, nor comparing them. For instance, a number of studies with animals and children (Amsel, 1958; Ryan \& Watson, 1968) showed that a violation of expectations in the form of a non-reward (i.e., the withholding of a reward) leads to an increase in vigor of the subsequent behavior. This line of research fails to provide clear support for an effect of expectancy on emotions for two reasons. First, many of these studies confound expectancy with goal congruence because they contrast non-rewards with rewards (Amsel, 1958; Ryan \& Watson, 1968). Second, expectancy is often manipulated together with proximity. For instance, Haner and Brown (1955) instructed children to fill a marble board in order to win a prize. At varying distances from the goal, the experimenter pushed a handle to release all marbles. The closer participants were to the goal, the more force they used to push a plunger that stopped a noise that was initiated together with the release of the marbles (see also, 
Endsley, 1966; Pederson \& Mcewan, 1970; for one replication and one failed replication). In this study, participants' expectation to reach the goal was manipulated by their proximity to the goal.

Studies with adult participants can be found in the gambling literature on the near-miss effect. Just missing a win when gambling seems to increase the motivation to continue gambling, both in laboratory studies (Clark, Crooks, Clarke, Aitken, \& Dunn, 2012; Côté, Caron, Aubert, Desrochers, \& Ladouceur, 2003; Qi, Ding, Song, \& Yang, 2011) and in real life (Ariyabuddhiphongs \& Phengphol, 2008). Again, most operationalizations of near-misses confounded the appraisals of expectancy and proximity. For instance, in a slot machine game by Clark et al. (2012) near-misses were trials on which the winning symbol stopped at one position from the payline (high expectation to win, high proximity) and full-misses were trials on which the winning symbol stopped at a position further away from the payline (low expectation to win, low proximity). Some studies did succeed at manipulating expectancy unconfounded with proximity. Strickland and Grote (1967) manipulated the proportion of unexpected goalincongruent trials in a slot machine game in which three winning symbols led to a monetary gain. One group of participants was exposed to many unexpected goal-incongruent trials: Winning symbols appeared frequently in the first slot but infrequently in the last slot. Another group of participants was exposed to many expected goal-incongruent trials: Winning symbols appeared frequently in the last slot but infrequently in the first slot. They found that participants in the first group had a stronger tendency to continue gambling than participants in the second group (but see Reid, 1986, for a failed replication).

To summarize, existing research suggests that unexpected (high prior expectations of reaching the goal) and proximal (almost reaching the goal) goal-incongruent outcomes are associated with an increased readiness to act compared to expected and distal goal-incongruent 
outcomes. To date, it remains unclear whether both the appraisals of expectancy and proximity contribute to this effect or whether it is driven primarily by one of the two variables. In addition, it remains unclear whether these appraisals result in a general increase of motivation or whether they activate specific action tendencies.

\section{The Feeling Component}

The unexpectedness of an event often is considered a general amplifier of positive and negative feelings. For instance, Kahneman and Miller (1986) proposed that abnormal events (e.g., events that violate expectations) produce more intense feelings. This idea was supported in studies in which expectations were measured (McGraw, Mellers, \& Ritov, 2004; Siemer, Mauss, \& Gross, 2007) or experimentally manipulated (Mellers, Schwartz, Ho, \& Ritov, 1997; Shepperd \& McNulty, 2002; van Dijk \& van der Pligt, 1997). These studies suggest that it is always better to expect the worse: Expecting the occurrence of a goal-incongruent event (a) attenuates negative feelings when the goal-incongruent event (expectedly) does occur and (b) increases positive feelings when a goal-congruent event (unexpectedly) occurs. On the other hand, expecting the occurrence of a goal-congruent event (a) attenuates positive feelings when the goal-congruent event (expectedly) does occur and (b) increases negative feelings when a goal-incongruent event (unexpectedly) occurs (McGraw, Mellers, \& Tetlock, 2005). In several of these studies, however, the effects also can be explained by differences in proximity (e.g., McGraw, et al., 2004; Mellers, et al., 1997; Siemer, et al., 2007). Moreover, a number of other studies have failed to show that prior expectations influence the intensity of positive and negative feelings (Feather \& Simon, 1971; Golub, Gilbert, \& Wilson, 2009; Marshall \& Brown, 2006; but see Sweeny \& Shepperd, 2010, for a reply). 
In a variety of contexts such as sports (Markman, McMullen, \& Elizaga, 2008), gambling (Clark, et al., 2012; Clark, Lawrence, Astley-Jones, \& Gray, 2009; Qi, et al., 2011), and study grades (Medvec \& Savitsky, 1997), negative feelings in face of goal-incongruent outcomes seem to be more intense when a goal-congruent outcome is proximal. On the other hand, there are reasons to believe that being close to a goal-congruent outcome partly releases the positive valence tied to the goal-congruent outcome, even when the outcome is missed (Dixon \& Schreiber, 2004; Reid, 1986; Skinner, 1953). Near-misses in gambling seem to activate the same brain areas as wins (Clark, et al., 2009) and are associated with a reduced feedback-related negativity in event-related potentials compared to full-misses (Luo, Wang, \& Qu, 2011). Again, few studies clearly separated the influence of expectancy and proximity (but see Medvec \& Savitsky, 1997).

To summarize, previous research did not produce a clear pattern of results with respect to the influence of expectancy and proximity on the intensity of negative feelings. The disparity in the literature partly may be due to the fact that few studies clearly separated the two variables.

\section{The Present Research}

We set up three experiments in which we examined the separate influence of expectancy and proximity on emotions. The experiments were designed as slot machine games that participants played for actual money. Each experiment consisted of a series of trials and each trial started with the sequential presentation of three pieces of fruit, in one of four combinations: (a) a win trial (AAA: three times the same fruit), (b) an unexpected proximal loss trial (AAB: two times the same fruit followed by a different fruit), (c) an expected proximal loss trial (ABA/ABB: two times the same fruit in Slots 1 and 3 or in Slots 2 and 3), and (d) an expected distal loss trial (ABC: three times a different fruit). Emotions were measured via the motivational 
component and the feeling component. For the motivational component, we measured the tendency to repair a loss or goal-incongruent outcome. Repairing can be regarded as a problemsolving behavior that is usually not harmful (unlike risk taking or gambling). The tendency to repair was measured trial by trial, by registering the extent to which participants took the opportunity to play a repair game on the loss trials. Participants also self-reported on the tendency to repair on the different trial types at the end of the experiment. For the feeling component, participants reported on their feelings of disappointment, frustration, and anger at the end of the experiment (Experiments 1 and 2) or trial by trial (Experiment 3). In Experiments 1 and 2 , the feeling component was measured retrospectively to avoid (a) interference with the trial-by-trial assessment of the motivational component and (b) demand effects when participants would become aware that we measured their emotions. In Experiment 3, the feeling component was measured trial by trial because retrospective measures have been shown to suffer from a number of biases (Barrett, 1997; Robinson \& Clore, 2002).

Although feelings and action tendencies were only measured in response to the displays with three fruit symbols, we considered it likely that participants updated their appraisals along with the presentation of each new symbol. More specifically, it can be assumed that all fruit symbols appearing in the first position would be appraised similarly, given that they all yielded an equal chance at winning and appeared equally frequently in the first position. The second symbol introduced novel information and may have caused expectations (AA trials vs. AB trials may have caused the expectation of a win vs. a loss) and appraisals of goal congruence (AA trials vs. AB trials as goal congruent vs. goal incongruent). The third symbol, together with the information that the trial was a loss vs. a win trial, may have caused (changes in) the appraisals of goal congruence (goal congruent vs. goal incongruent), expectancy (unexpected vs. expected), 
and proximity (proximal vs. distal). With regard to the third symbol, we assumed that even if participants saw combination $\mathrm{AB}$ and thus knew that the trial was a loss trial, they would still update their appraisals according to the last symbol (A/B vs. C) and thus would appraise the proximity of the current outcome to the goal-congruent outcome. This assumption was based on the famous missed flight example of Kahneman and Tversky (1982). In the example, two men arrive at the airport 30 minutes after the scheduled departure time of their respective flights. One person is told that his flight left on time and the other person is told that, because of a delay, his flight left only five minutes ago. The researchers predicted that although both missed their flight, the latter person would feel more upset. This can only be the case if the appraisal process continues after the goal-incongruent outcome is definitive. To check whether participants indeed updated their appraisals along with the presentation of the second and third symbols, we asked them to rate the goal congruence of the two-fruit displays and of the three-fruit displays. Feelings and action tendencies were measured in response to the three-fruit displays because only when all three symbols were presented, it became clear whether the trial was a win trial vs. an unexpected proximal loss trial, or an expected proximal loss trial vs. an expected distal loss trial. In other words, only the emotional response locked on the third symbol could be used to calculate the effects of interest.

Experiments 1 and 2 had a similar procedure but with small variations in trial distribution. In Experiment 1, participants received an equal number of $\mathrm{AAB}$ trials, $\mathrm{ABA} A \mathrm{ABB}$ trials, and $\mathrm{ABC}$ trials (see Table 1). This way of counterbalancing has the (statistical) advantage that each cell of the design contained an equal number of trials and that the effects of trial type as well as the specific effects of expectancy and proximity could be calculated on an equal number of trials. A potential drawback of this design, however, was that the total number of unexpected 
loss trials $(\mathrm{AAB})$ was lower than the total number of expected loss trials (ABA/ABB plus $\mathrm{ABC}$ ) and that the total number of proximal loss trials (AAB plus $\mathrm{ABA} / \mathrm{ABB}$ ) was higher than the total number of distal loss trials (ABC). To warrant an interpretation of our effects in terms of expectancy and proximity rather than in terms of differences in trial frequency, a different counterbalancing procedure was employed in Experiment 2. In this experiment, half of the participants received an equal number of unexpected and expected loss trials (i.e., the number of $\mathrm{AAB}$ trials was equal to the sum of $\mathrm{ABA} / \mathrm{ABB}$ and $\mathrm{ABC}$ trials) whereas the other half received an equal number of distal and proximal loss trials (i.e., the number of $\mathrm{ABC}$ trials was equal to the sum of $\mathrm{ABA} / \mathrm{ABB}$ and $\mathrm{AAB}$ trials). In Experiment 3, we employed the same counterbalancing procedure as in Experiment 1 but measured feelings online rather than retrospectively.

\section{Experiment 1}

\section{Method}

\section{Participants.}

Thirty-seven students at Ghent University $\left(M_{\text {age }}=22,4\right.$ males $)$ participated in the experiment in return for payment ( $8 €$, augmented with the amount they won in the game). The students in this sample had a moderate to high experience with gambling in general $(M=4.92$, $S D=1.93)$ but a low experience with slot machines $(M=2.00, S D=1.27)$, as was evident from their ratings on scales ranging from 1 (completely not experienced) to 7 (very experienced).

\section{Materials.}

The experiment was programmed and run in Affect 4.0 (Spruyt, Clarysse, Vansteenwegen, Baeyens, \& Hermans, 2010). It was administered on a computer connected to a keyboard, a 19" CRT screen, two speakers, and a mouse-shaped response box (Voss, Leonhart, 
\& Stahl, 2007). Other materials in the room were a transparent money bank and a bag filled with ten-cent coins.

The slot machine presented on the computer screen consisted of three parts (see Figure 1). The upper part contained the slots in which the fruits appeared. The middle part contained three information boxes, from left to right labeled as "credits" (with the number of available credits), "bet" (with the number of betted credits on a particular trial), and "winning bet" (the number of credits needed to repair a goal-incongruent outcome; this information appeared only after a successful bet in the repair game). The lower part contained three spin buttons (in the first phase of each trial) or a feedback message (in the second phase of each trial).

\section{Design.}

The experiment consisted of 9 win trials (AAA), 48 unexpected proximal loss trials (AAB), 48 expected proximal loss trials (24 ABA, $24 \mathrm{ABB})$, and 48 expected distal loss trials (ABC; see Table 1).

\section{Procedure.}

All participants were tested individually in a session of 45 minutes. The participant was seated at a table facing the CRT screen, holding the left hand on the numerical part of the keyboard and the right hand (index and middle finger) on the response box. The experimenter was seated at a table placed orthogonally to the participants' table and was unable to see the computer screen. The money bank was positioned between the participant and the experimenter and was visible to both. At the start of the experiment, participants had no money but received 1200 credits to bet throughout the experiment.

The experiment consisted of 153 trials presented in a random order in three blocks of 51 trials. At trial start, the slot machine had three empty slots. Under each slot, there was a button 
with the word "spin". When the participant pressed numerical key "1", the spin button under the first slot was activated (indicated by a yellow border that appeared around the button) and the slot machine spun the wheel of the first slot for a time interval between 500 and $1500 \mathrm{~ms}$ (together with the sound of a spinning wheel) until a piece of fruit appeared (together with a clicking sound). After the first fruit appeared, the participant could press numerical key " 2 " to activate the spin button under the second slot. After the second fruit appeared, the participant could press numerical key " 3 " to activate the spin button under the third slot. The pictures of pieces of fruit that could appear in the slots were a lemon $(\mathrm{L})$, a prune $(\mathrm{P})$, and a melon $(\mathrm{M})$. They could appear in one of the following five combinations: AAA, AAB, ABA, ABB, or ABC. On each trial, the three pictures were assigned randomly to the function of $\mathrm{A}, \mathrm{B}$, and $\mathrm{C}$. The three pieces of fruit remained on screen together for $1000 \mathrm{~ms}$ before a win feedback message ("10 cent", printed in green) or a loss feedback message ("0 cents", printed in red) appeared in the bottom part of the slot machine, replacing the spin buttons. The win feedback was accompanied by a positive sound and a deposit of ten cents by the experimenter in the money bank. The loss feedback was accompanied by pictures of two red buttons that appeared simultaneously on the screen and that were tagged "second chance" (left button) and "pass" (right button). Participants could choose a second chance or could pass by clicking the corresponding left or right button of the response box. When participants chose to pass, the next trial started $1000 \mathrm{~ms}$ later and a negative sound was played. When participants chose for a second chance, they could bet a number of credits to repair the goal-incongruent outcome. The start bet was ten credits. Participants could choose to bet ten or more credits. When the second chance button was clicked for the first time, the start bet was made and the pass button turned into a stop button (i.e., the word "pass" was replaced by the word "stop"). Each additional click on the second chance 
button increased the bet by one credit and decreased the available credits by one. When participants pressed the stop button, the two buttons disappeared and the computer compared the number of betted credits to a random number between zero and fifty. If the bet was equal to or exceeded the random number, the win feedback message and the random number were displayed, a positive sound was played, and the experimenter made a deposit of ten cents. If the bet was lower than the random number, the loss feedback message remained on screen and a negative sound was played (the random number was not shown). The feedback remained on screen for $3000 \mathrm{~ms}$ before a new trial started.

Prior to the experiment, participants received written and oral instructions, a demonstration trial, and a practice trial (both $\mathrm{ABC}$ trials). On the demonstration trial, the experimenter demonstrated how the participant could repair the negative outcome and explained that higher bets yielded a higher chance at winning (a bet of 10 credits was said to correspond to a low chance at winning, 15 credits to a slightly higher chance, 25 credits to a chance of $50 \%, 35$ credits to substantially more than $50 \%$ chance, and 50 credits to a $100 \%$ chance). The practice trial was identical to the experimental trials, except that participants could not win money nor lose credits (the number of available credits was reset to 1200 after the practice trial). Before the actual experiment, the participant was instructed to use the 1200 credits in a sparing way, more specifically, to spend them equally across the three blocks of the experiment (i.e., \pm 400 credits per block). After each block, the game paused and the number of available credits was displayed. The experimenter then evaluated whether the participant had followed the instructions and, if not, repeated them.

After the experiment, a questionnaire was administered in which different trial types were rated on scales ranging from 1 (not at all) to 7 (yes completely). The questionnaire displayed the 
different trial types in a sequential manner: the two-fruit display LL was followed by the threefruit displays LLL and LLM; the two-fruit display LM was followed by the three-fruit displays LML and LMP. The two-fruit displays were added as a manipulation check. They allowed us to test (a) whether the expectation of winning was higher for LL displays than for LM displays and (b) whether participants updated their appraisals (more specifically, the appraisal of goal congruence) from the second to the third symbol or whether on some trials (e.g., LM trials) the third symbol was ignored. For the two-fruit displays LL and LM, participants rated their expectation of winning ten cents ("to what extent do you expect to win 10 cents?") and their appraisal of goal congruence (“to what extent do you think the situation is positive?"). For all loss displays (LLM, LML, and LMP), participants rated the appraisal of goal congruence, negative feelings (anger, disappointment, and frustration), the tendency to pass, the tendency to choose a second chance, the number of credits they wanted to bet in the repair game, and the appraisal of coping potential ("when you bet 25 credits in the repair game, to what extent do you expect to win back the ten cents in the repair game?"). The latter appraisal was included to examine whether any effects of expectancy or proximity were moderated or mediated by coping potential. If participants would appraise their coping potential as higher on unexpected proximal losses than on expected distal losses, this could explain a higher tendency to repair on the former than on the latter trials. The questionnaire was administered in three versions to counterbalance the order of appearance of the different trial types: In the first version the order was LL(M), LL(L), LM(L), and LM(P); in the second version it was LM(L), LM(P), LL(M), and LL(L); and in the third version it was $\operatorname{LM}(\mathrm{P}), \mathrm{LM}(\mathrm{L}), \mathrm{LL}(\mathrm{M})$, and $\mathrm{LL}(\mathrm{L})$. After completion of the questionnaire, participants were thanked and debriefed and the money in the money bank was exchanged for bigger coins. 


\section{Results}

\section{Analyses.}

For each dependent variable, we first conducted a repeated measures MANOVA with the within-subjects variable trial type (unexpected proximal or $\mathrm{AAB}$, expected proximal or $\mathrm{ABA} / \mathrm{ABB}$, and expected distal or $\mathrm{ABC})$. Second, to investigate the unique effect of expectancy, we used planned comparisons to contrast unexpected proximal trials (AAB) with expected proximal trials (ABA/ABB). Third, to investigate the unique effect of proximity, we used planned comparisons to contrast expected proximal trials (ABA/ABB) with expected distal trials (ABC). Fourth, to examine whether the effect of expectancy was significantly different from the effect of proximity, we used polynomial contrasts to test for a quadratic trend in the relation between $\mathrm{AAB}, \mathrm{ABA} / \mathrm{ABB}$, and $\mathrm{ABC}$ trials. A table of means and standard deviations for these analyses is presented in Table 2. Fifth, we inspected the correlations between the effects of expectancy on the different dependent variables and similarly for the effects of proximity (see Table 3). More specifically, we correlated the difference scores representing the effects of expectancy on the various dependent variables with each other, for example, the effect of expectancy on the percentage of choosing a second chance (i.e., the difference between the percentage of choosing a second chance on $\mathrm{AAB}$ minus $\mathrm{ABA} / \mathrm{ABB}$ trials) with the effect of expectancy on ratings of disappointment (i.e., the difference between feelings of disappointment on $\mathrm{AAB}$ minus $\mathrm{ABA} / \mathrm{ABB}$ trials). Similarly, we correlated the effects of proximity on the various dependent variables with each other. Finally, we investigated whether differences in coping potential could explain the effects of expectancy and proximity. It may be noted that we did not examine the interaction between expectancy and proximity, because our design did not 
contain unexpected distal trials. Before turning to the results of these analyses, we report the results of a manipulation check.

\section{Manipulation check.}

A repeated measures ANOVA revealed that participants' expectation of winning ten cents was significantly higher on LL trials $(M=4.41, S D=1.09)$ than on LM trials $(M=2.43$, $S D=1.37), F(1,36)=58.28, p<.001, \eta_{p}^{2}=.62$. Moreover, the LL display was rated as more goal congruent $(M=5.22, S D=1.11)$ than the LM display $(M=3.05, S D=2.05), F(1,36)=$ $35.18, p<.001 \eta_{p}^{2}=.49$.

To test whether participants updated their appraisals from the second to the third symbol on LM trials (despite knowing that the trial would be a loss trial), we compared the appraisal of goal congruence on (a) the LML vs. LMP displays, (b) the LM vs. LML displays, and (c) the LM vs. LMP displays. A repeated measures ANOVA revealed that LML trials were rated as significantly more goal congruent $(M=3.27, S D=1.72)$ than LMP trials $(M=2.30, S D=1.73)$, $F(1,36)=7.08, p=.012, \eta^{2}=.16$. Further analyses showed that the appraisal of goal congruence decreased marginally from LM displays to LMP displays $(M=2.62, S D=1.83)$, $F(1,36)=4.08, p=.051, \eta_{p}^{2}=.10$, and did not change from LM displays $(M=3.05, S D=2.05)$ to LML displays $(M=3.24, S D=2.83), F(1,36)=0.83, p=.37, \eta^{2}{ }_{p}=.022$.

\section{Influence of expectancy and proximity on the tendency to repair.}

The tendency to repair was measured via repair behavior (online) and via self-reports (at the end of the experiment). We discuss the results for each measure as well as the correlations between the measures.

Behavioral measures. We analyzed two aspects of repair behavior: (a) the percentage of choosing for a second chance and (b) the average bet placed after choosing for a second chance. 
The analysis of the percentage of choosing a second chance revealed a significant effect of trial type, $F(2,35)=7.07, p=.003, \eta^{2} p=.29$. Choosing a second chance was both influenced by expectancy (i.e., participants more often chose a second chance on unexpected proximal or AAB trials than on expected proximal or $\mathrm{ABA} / \mathrm{ABB}$ trials $), F(1,36)=6.37, p=.016, \eta^{2}=.15$, and by proximity (i.e., participants more often chose a second chance on expected proximal or $\mathrm{ABA} / \mathrm{ABB}$ trials than on expected distal or $\mathrm{ABC}$ trials), $F(1,36)=8.48, p=.006, \eta^{2}=.19$ (see Table 2). The effect of proximity was not significantly different from the effect of expectancy, $F(1,36)=1.93, p=.17, \eta_{p}^{2}=.051($ see Table 2$)$.

The analysis of the average bet after choosing for a second chance revealed a trend effect of trial type, $F(2,32)=2.61, p=.089, \eta^{2} p=.14$. There was a trend effect of expectancy (i.e., the average bet was higher on unexpected proximal or AAB trials than on expected proximal or ABA/ABB trials), $F(1,33)=3.28, p=.079, \eta_{p}^{2}=.090$. The effect of proximity was not significant, $F(1,33)=1.03, p=.75, \eta^{2} p=.003$. There was no significant difference between the influence of expectancy and proximity, $F(1,33)=0.45, p=.51, \eta_{p}^{2}=.013$ (see Table 2 ).

Self-reports. Three items of the questionnaire reflected the tendency to repair: (a) the tendency to choose a second chance, (b) the tendency to pass, and (c) the number of betted credits. The self-reported tendency to choose a second chance was significantly influenced by trial type, $F(2,35)=7.10, p=.003, \eta_{p}^{2}=.29$. There was a significant effect of expectancy (i.e., participants reported a stronger tendency to choose a second chance on unexpected proximal or AAB trials than on expected proximal or ABA trials), $F(1,36)=6.61, p=.014, \eta^{2}{ }_{p}=.16$, a trend effect of proximity (i.e., participants reported a stronger tendency to choose a second chance on expected proximal or $\mathrm{ABA}$ trials than on expected distal or $\mathrm{ABC}$ trials), $F(1,36)=3.56, p=$ 
$.067, \eta^{2}{ }_{p}=.09$, and no difference between the two effects, $F(1,36)=.047, p=.83, \eta^{2}{ }_{p}=.001$ (see Table 2).

For the tendency to pass, there was again a significant effect of trial type, $F(2,35)=4.24$, $p=.022, \eta^{2}{ }_{p}=.20$. The effect of expectancy failed to reach significance, $F(1,36)=2.21, p=.15$, $\eta_{p}^{2}=.058$, but the effect of proximity again reached significance (i.e., the tendency to pass was lower on expected proximal $\mathrm{ABA}$ or trials than on expected distal or $\mathrm{ABC}$ trials), $F(1,36)=$ $4.58, p=.039, \eta_{p}^{2}=.11$. There was no difference between the two effects, $F(1,36)=0.40, p=$ $.53, \eta_{p}^{2}=.11$ (see Table 2).

For the number of betted credits, there was no global effect of trial type, $F(2,35)=3.74$, $p=.34, \eta^{2}{ }_{p}=.18$. Nevertheless, the effect of expectancy was significant (i.e., self-reported bets were higher on unexpected proximal or AAB trials than on expected proximal or ABA trials), $F(1,36)=5.71, p=.022, \eta_{p}^{2}=.14$. The effect of proximity was not significant, $F(1,36)=1.14$, $p=.29, \eta^{2}{ }_{p}=.03$, but did not differ significantly from the effect of expectancy, $F(1,36)=.075, p$ $=.79, \eta_{p}^{2}=.002($ see Table 2$)$.

Correlations. Both for the effects of expectancy and proximity, we examined the correlations (a) among the effects obtained with the two behavioral measures of the tendency to repair, (b) among the effects obtained with the three self-report measures of the tendency to repair, and (c) between the effects obtained with both types of measures. For the effects of expectancy, only two correlations reached significance: The effect of expectancy on the selfreported tendency to pass correlated negatively with the effect of expectancy on the self-reported tendency to choose a second chance and negatively with the effect of expectancy on the selfreported bet (see Table 3). 
For the effects of proximity the data pattern was slightly different. The correlation among the behavioral measures again did not reach significance, but all correlations among the selfreport measures were significant (see Table 3). Additionally, there were significant correlations between the effects of proximity on the tendency to repair as measured by behavior and as measured by self-reports: The effect of proximity on all three self-report scales correlated significantly with the effect of proximity on the percentage of choosing a second chance, and the effect of proximity on the self-reported bet correlated with the effect of proximity on the actual bet (see Table 3).

\section{Influence of expectancy and proximity on negative feelings.}

We examined the influence of expectancy and proximity on the self-reported feelings of disappointment, frustration, and anger. For disappointment, we found a significant effect of trial type, $F(2,35)=11.96, p<.001, \eta_{p}^{2}=.41$. As can be seen in Table 2, the effect of expectancy was significant (i.e., participants felt more disappointment on unexpected proximal or AAB trials than on expected proximal or ABA trials), $F(1,36)=20.54, p<.001, \eta_{p}^{2}=.36$, but the effect of proximity failed to reach significance, $F(1,36)=0.31, p=.58, \eta^{2}{ }^{2}=.009$. The effect of expectancy was significantly stronger than the effect of proximity, $F(1,36)=6.45, p=.016, \eta^{2} p$ $=.15$.

A similar pattern of results emerged for frustration: There was a significant effect of trial type, $F(2,35)=8.12, p=.001, \eta_{p}^{2}=.317$, a significant effect of expectancy (i.e., participants felt more frustration on unexpected proximal or $\mathrm{AAB}$ trials than on expected proximal or $\mathrm{ABA}$ trials), $F(1,36)=11.24, p=.002, \eta^{2}{ }_{p}=.24$, and no effect of proximity, $F(1,36)=2.57, p=.12$, $\eta_{p}^{2}=.067$. The difference between the two was marginally significant, $F(1,36)=3.02, p=.091$, $\eta_{p}^{2}=.077($ see Table 2$)$ 
For anger there was also a significant effect of trial type, $F(2,35)=9.05, p=.001, \eta^{2}{ }^{2}=$ .34. The effect of expectancy was significant (i.e., participants felt more anger on unexpected proximal or AAB trials than on expected proximal or ABA trials), $F(1,36)=18.59, p<.001, \eta^{2} p$ $=.34$, and the effect of proximity was not, $F(1,36)=0.00$. The effect of proximity differed significantly from the effect of expectancy, $F(1,36)=8.40, p=.006, \eta_{p}^{2}=.19$ (see Table 2 ).

Both for the effects of expectancy and proximity, we examined the correlations among the different negative feelings as well as between these feelings and the tendency to repair. The effects of expectancy on disappointment, frustration, and anger were highly interrelated (see Table 3). The same held for the effects of proximity on anger and frustration and the effects of proximity on anger and disappointment. There were no significant correlations between feelings and the tendency to repair (neither for the effects of expectancy, nor for the effects of proximity, Table 3).

\section{Role of coping potential.}

We investigated whether differences in the appraisal of coping potential moderated or mediated the effects of the appraisals of expectancy and proximity on the tendency to repair and on negative feelings. First, we investigated whether expectancy or proximity had an influence on coping potential. Coping potential differed significantly across the trial types, $F(2,35)=3.47, p$ $=.042, \eta_{p}^{2}=.17$. There was a significant effect of expectancy: Participants rated their coping potential as higher on unexpected proximal or AAB trials $(M=4.49, S D=1.04)$ than on expected proximal or ABA trials $(M=4.16, S D=1.01), F(1,36)=6.34, p=.016, \eta^{2}{ }_{p}=.15$. There was no effect of proximity: Coping potential was rated as equally high on expected proximal or ABA trials $(M=4.16, S D=1.01)$ and on expected distal or ABC trials $(M=4.22$, $S D=1.03), F<1$. To examine whether the effect of expectancy on any of the dependent 
variables was mediated, moderated, or unaffected by coping potential, we regressed the difference between $\mathrm{AAB}$ trials and $\mathrm{ABA}$ trials for each dependent variable on two predictors: (a) the centered sum score of coping potential on AAB trials and ABA trials and (b) the difference score in coping potential on AAB trials and ABA trials (Judd, Kenny, \& McClelland, 2001). The interpretation of this analysis is as follows (Judd, et al., 2001): (a) If the difference score of the dependent variable is significantly predicted by the centered sum score of coping potential, then coping potential moderates the effect of expectancy; (b) if the difference score of the dependent variable is significantly predicted by the difference score of coping potential, then coping potential mediates the effect of expectancy; (c) if the intercept is significant, the residual effect of expectancy is significant over and above the difference in coping potential. We executed eight regressions for each of the difference scores of the dependent variables (disappointment, frustration, anger, frequency of choosing a second chance, average bet, self-reported bet, selfreported tendency to choose a second chance, and self-reported tendency to pass). For none of the eight variables we found support for a moderation effect, $t \mathrm{~s}<1$. We did find support for a mediation effect for two dependent variables: the self-reported bet, $\beta=.39, t(36)=2.46, p=$ .019 , and the self-reported tendency to choose a second chance, $\beta=.34, t(36)=2.08, p=.045$. The positive regression weights indicate that the more participants estimated their coping potential as higher on $\mathrm{AAB}$ trials than on $\mathrm{ABA}$ trials, the more their self-reported tendency to repair was increased on $\mathrm{AAB}$ trials compared to ABA trials. There was no residual effect of expectancy for the self-reported bet, $t(36)=1.39 p=.18$, nor for the self-reported tendency to choose a second chance, $t(36)=1.64, p=.11$, suggesting full mediation. The effects of none of the other variables were mediated by coping potential, $t \mathrm{~s}<1$.

\section{Discussion}


The results of the first experiment suggest that the appraisals of expectancy and proximity both influence emotional responding to goal-incongruent events. Expectancy and proximity separately augmented the tendency to repair: Both variables affected the decision to engage in repair behavior (i.e., to take a second chance) and expectancy additionally had a marginal effect on the number of credits that were invested subsequently. Data on the selfreported tendency to repair largely confirmed this pattern. The absence of correlations between the tendency to repair as measured by self-reports and as measured by behavior may indicate that participants' behavior was influenced by additional factors that did not influence self-reported action tendencies (such as strategic influences) or that participants did not (or could not) accurately report on their action tendencies.

A different pattern of results emerged for feelings of disappointment, frustration, and anger. All feelings remained largely unaffected by proximity but were significantly increased by expectancy. Additional analyses suggested that most of our results could not be attributed to differences in coping potential, except in the case of an influence of expectancy on the selfreported tendency to repair: Participants appraised their coping potential to be higher on unexpected than on expected loss trials and this difference mediated the effects of expectancy on the self-reported tendency to repair.

To ascertain that our results generalized across different trial distributions, we conducted a second experiment in which trial distribution was directly manipulated. In Experiment 1, the amount of unexpected proximal loss or $\mathrm{AAB}$ trials, expected proximal loss or $\mathrm{ABA} / \mathrm{ABB}$ trials, and expected distal loss or ABC trials was balanced (i.e., each trial type occurred 48 times). This way of counterbalancing implied, however, that the frequency of expected loss trials (i.e., $\mathrm{ABA} / \mathrm{ABB}$ plus $\mathrm{ABC}$ trials, 96 trials in total) was higher than the frequency of unexpected loss 
trials (i.e., AAB trials, 48 in total) and that the frequency of proximal loss trials (i.e., ABA/ABB plus $\mathrm{AAB}$ trials, 96 trials in total) was higher than the frequency of distal loss trials (i.e., ABC trials, 48 in total, see Table 1). This leaves open a number of alternative explanations for the findings of Experiment 1. For example, the finding that only expectancy influenced feelings of disappointment, frustration, and anger could be explained by the fact that the amount of unexpected loss trials was relatively low (i.e., 48 trials) compared to the amount of proximal trials (i.e., 96 trials). Mere exposure to frequent events (e.g., trials starting with AB) may have diminished negative feelings to those events compared to infrequent ones (e.g., trials starting with AA). In other words, this finding could reflect a habituation effect instead of an effect of expectancy. In Experiment 2, we employed two new manipulations of trial distribution. In a first condition, we matched the number of expected and unexpected loss trials. In a second condition, we matched the number of proximal and distal loss trials. Replication of the effects of Experiment 1 across the different trial distributions would allow us to safely conclude that the obtained effects were a function of the manipulations of expectancy and proximity rather than of differences in trial frequencies.

\section{Experiment 2}

\section{Method}

\section{Participants.}

Thirty first-year psychology students at Ghent University $\left(M_{\text {age }}=19,8\right.$ males $)$ participated in the experiment in return for course credits. As in Experiment 1, the students had a moderate to high experience with gambling in general $(M=5.00, S D=1.74)$ but a low experience with slot machines $(M=2.00, S D=1.20)$.

\section{Design.}


The experiment consisted of two between-subjects conditions (see Table 1): The first condition had 72 unexpected proximal loss trials (AAB), 36 expected proximal loss trials (18 ABA trials, 18 ABB trials), and 36 expected distal loss trials (ABC). The second condition had 36 unexpected proximal loss trials (AAB), 36 expected proximal loss trials (18 ABA trials, 18 ABB trials), and 72 expected distal loss trials (ABC). In all conditions, participants received 9 win trials (AAA trials). For ease of communication, in the remainder of the text we refer to these two conditions as the 72-AAB/36-ABC condition and the 36-AAB/72-ABC condition respectively.

\section{Procedure.}

The procedure was identical to the procedure of Experiment 1, except that the item for coping potential was not included in the questionnaire.

\section{Results}

\section{Analyses.}

The analyses of Experiment 2 were identical to the analyses of Experiment 1, except that the between-subjects factor trial distribution was added to the repeated measures MANOVA.

\section{Manipulation check.}

A Trial Type (LL vs. LM) x Trial Distribution analysis for the ratings of the expectation to win ten cents revealed a main effect of trial type, $F(1,28)=33.69, p<.001, \eta^{2}{ }_{p}=.55$, no main effect of trial distribution, nor an interaction between trial type and trial distribution, $F s<1$. Participants had a higher expectation of winning ten cents on LL trials $(M=4.47, S D=1.25)$ than on LM trials $(M=2.27, S D=1.36)$. Additionally, a Trial Type (LL vs. LM) x Trial Distribution analysis for the ratings of goal congruence suggested that the LL display was rated as more positive $(M=5.31, S D=1.34)$ than the LM display $(M=2.62, S D=1.78), F(1,28)=$ 
$42.50, p<.001, \eta_{p}^{2}=.60$. There was no influence of trial distribution on the ratings of goal congruence, $F \mathrm{~s}<1$.

An analysis of Trial Type (LML vs. LMP) x Trial Distribution for the ratings of goal congruence revealed a main effect of trial type, $F(1,28)=10.05, p=.004, \eta^{2} p=.26$. This suggests that participants did not ignore the third and last symbol on LM trials. Conform the pattern of results in Experiment 1, LML trials were rated as more goal congruent $(M=3.24, S D$ $=1.83)$ than LMP trials $(M=2.62, S D=1.83)$. There was no main effect of trial distribution nor an interaction between trial type and trial distribution, $F_{\mathrm{s}}<1.06, p s>.31$. Further analyses revealed that the appraisal of goal congruence increased significantly from $\operatorname{LM}(M=2.60, S D=$ 1.75) to $\operatorname{LML}(M=3.27, S D=1.72), F(1,28)=5.82, p=.023, \eta^{2}{ }_{p}=.17$, and did not change from $\operatorname{LM}$ to $\operatorname{LMP}(M=2.30, S D=1.73), F(1,28)=2.42, p=.14 \eta_{p}^{2}=.08$.

\section{Influence of expectancy and proximity on the tendency to repair.}

The tendency to repair was measured via repair behavior (online) and via self-reports (at the end of the experiment). We discuss the results for each measure in turn.

Behavioral measures. We analyzed two aspects of repair behavior across the different trial types: (a) the percentage of choosing for a second chance and (b) the average bet placed after choosing for a second chance. The Trial Type $\mathrm{x}$ Trial Distribution analysis for the percentage of choosing a second chance revealed a main effect of trial type, $F(2,27)=10.18, p=$ $.001, \eta_{p}^{2}=.43$, a main effect of trial distribution, $F(1,28)=6.98, p=.013, \eta_{p}^{2}=.20$, and no interaction between trial type and trial distribution, $F(2,27)=0.93, p=.41, \eta_{p}^{2}=.065$. Choosing a second chance was marginally influenced by expectancy (i.e., participants more often chose a second chance on unexpected proximal or $\mathrm{AAB}$ trials than on expected proximal or $\mathrm{ABA} / \mathrm{ABB}$ trials), $F(1,28)=3.59, p=.069, \eta_{p}^{2}=.11$, and was significantly influenced by proximity (i.e., 
participants more often chose a second chance on expected proximal or ABA/ABB trials than on expected distal or ABC trials), $F(1,28)=18.57, p<.001, \eta^{2}{ }_{p}=.40$ (see Table 2). The influence of proximity was significantly stronger than the influence of expectancy, $F(1,28)=5.30, p=$ $.029, \eta^{2}=.16$. (see Table 2). The main effect of trial distribution suggested that participants in the 36-AAB/72-ABC condition more often chose for a second chance $(M=46.14 \%, S D=11.27)$ than participants in the 72-AAB/36-ABC condition $(M=36.20 \%, S D=9.24)$.

The Trial Type $\mathrm{x}$ Trial Distribution analysis for the average bet after choosing for a second chance yielded no main effect of trial type, $F(2,26)=0.55, p=.58, \eta_{p}^{2}=.041$, nor of trial distribution, $F(2,26)=1.45, p=.24, \eta^{2}{ }_{p}=.051$, and no interaction between trial type and trial distribution, $F(2,26)=0.67, p=.52, \eta^{2} p=.049$. There was no effect of expectancy, $F(1,27)$ $=0.73, p=.40, \eta_{p}^{2}=.026$, no effect of proximity, $F(1,27)=0.20, p=.66, \eta^{2}{ }_{p}=.007$, and no difference between the effects of proximity and expectancy, $F(1,27)<0.01, p=.98$ (see Table 2).

Self-reports. We discuss the results for the three items of the questionnaire that reflected the tendency to repair: (a) the tendency to choose a second chance, (b) the tendency to pass, and (c) the number of betted credits. The Trial Type $x$ Trial Distribution analysis for the self-reported tendency to choose a second chance revealed a main effect of trial type, $F(2,27)=5.42, p=$ $.010, \eta_{p}^{2}=.29$, a marginal main effect of trial distribution, $F(1,28)=3.84, p=.06, \eta_{p}^{2}=.12$, and no interaction between trial type and trial distribution, $F(2,27)=1.23, p=.31, \eta_{p}^{2}=.084$. There was a significant effect of expectancy (i.e., a stronger tendency to choose a second chance on unexpected proximal or $\mathrm{AAB}$ trials than on expected proximal or $\mathrm{ABA}$ trials $), F(1,28)=4.57, p$ $=.041, \eta^{2}{ }_{p}=.14$, a significant effect of proximity (i.e., a stronger tendency to choose a second chance on expected proximal or $\mathrm{ABA}$ trials than on expected distal or $\mathrm{ABC}$ trials $), F(1,28)=$ 
$6.01, p=.021, \eta^{2} p=.18$, and no difference between the two effects, $F(1,28)=1.08, p=.31, \eta^{2} p$ $=.037$ (see Table 2). The marginal effect of trial distribution suggested that participants in the 36- $\mathrm{AAB} / 72-\mathrm{ABC}$ condition reported a higher tendency to choose a second chance $(M=4.69, S D$ $=0.96)$ those in the 72-AAB/36-ABC condition $(M=3.96, S D=1.09)$.

For the tendency to pass, there was a significant effect of trial type, $F(2,27)=5.61, p=$ $.009, \eta_{p}^{2}=.29$, a trend effect of trial distribution, $F(1,28)=3.91, p=.058, \eta_{p}^{2}=.12$, and no interaction between trial type and trial distribution, $F(2,27)=2.21, p=.13, \eta^{2}{ }_{p}=.14$. We again observed an effect of expectancy (i.e., a lower tendency to pass on unexpected proximal or AAB trials than on expected proximal or ABA trials), $F(1,28)=4.23, p=.049, \eta^{2} p=.13$, an effect of proximity (i.e., a lower tendency to pass on expected proximal or ABA trials than on expected distal or $\mathrm{ABC}$ trials), $F(1,28)=4.75, p=.038, \eta^{2} p=.15$, and no difference between the two effects, $F(1,28)=0.02, p=.88, \eta^{2}=.001$ (see Table 2). The trend effect of trial distribution suggests that participants in the $72-\mathrm{AAB} / 36-\mathrm{ABC}$ condition reported a higher tendency to pass $(M=4.24, S D=1.08)$ than those in the $36-\mathrm{AAB} / 72-\mathrm{ABC}$ condition $(M=3.47, S D=1.08)$.

For the number of betted credits, there was no main effect of trial type, $F(2,27)=2.43, p$ $=.11, \eta^{2}{ }^{2}=.15$, no main effect of trial distribution, $F(1,28)=0.09, p=.97, \eta^{2}{ }_{p}<.001$, and no interaction between trial type and trial distribution, $F(2,27)=0.55, p=.58, \eta_{p}^{2}=.039$. There was a trend effect of expectancy (i.e., higher bets on unexpected proximal or AAB than on expected proximal or ABA trials), $F(1,28)=2.94, p=.097, \eta^{2}{ }_{p}=.095$. The effect of proximity was not significant, $F(1,28)=0.75, p=.39, \eta_{p}^{2}=.026$, but was also not significantly different from the effect of expectancy, $F(1,28)=0.11, p=.74, \eta^{2} p=.004$ (see Table 2).

Correlations. Both for the effects of expectancy and proximity, we examined the correlations (a) among the effects on the two behavioral measures, (b) among the effects on the 
three self-report measures of the tendency to repair, and (c) between the effects on both types of measures. For the effects of expectancy, similar to Experiment 1, we observed significant correlations among a subset of the self-report measures but not among the behavioral measures (see Table 3). Unlike in Experiment 1, however, we did observe significant correlations between subsets of the self-report and behavioral measures: The effect of expectancy on the percentage of choosing a second chance was correlated with the effect of expectancy on the self-reported tendency to choose a second chance and with the effect of expectancy on the self-reported tendency to pass.

For the effects of proximity, the pattern of correlations was largely comparable to Experiment 1: There was no correlation among the behavioral measures, but all correlations among the self-report measures reached significance. Conform to Experiment 1, there were also several significant correlations between the effects of proximity on behavioral and self-report measures of the tendency to repair (see Table 3).

\section{Influence of expectancy and proximity on negative feelings.}

We examined the influence of expectancy and proximity on the feelings of disappointment, frustration, and anger. For disappointment, we found a significant effect of trial type, $F(2,27)=9.19, p=.001, \eta_{p}^{2}=.41$, no effect of trial distribution, $F(1,28)=0.19, p=.66$, $\eta_{p}^{2}=.007$, and no interaction between trial type and trial distribution, $F(2,27)=0.49, p=.62$, $\eta_{p}^{2}=.035$. As can be seen in Table 2 , the effect of expectancy was significant (i.e., participants felt more disappointment on unexpected proximal or AAB trials than on expected proximal or ABA trials), $F(1,28)=14.99, p=.001, \eta^{2} p=.35$. The effect of proximity failed to reach significance, $F(1,28)=0.10, p=.75, \eta_{p}^{2}=.004$. The effect of expectancy was marginally stronger than the effect of proximity, $F(1,28)=3.82, p=.061, \eta^{2}{ }_{p}=.12$. 
For frustration, there was no effect of trial type, $F(2,26)=0.49, p=.62, \eta^{2} p=.036$, nor of trial distribution, $F(1,27)=0.77, p=.39, \eta^{2} p=.028$, and no interaction between trial type and trial distribution, $F(2,26)=1.52, p=.24, \eta_{p}^{2}=.10$. The effect of expectancy was not significant, $F(1,27)=0.95, p=.34, \eta_{p}^{2}=.034$, nor was the effect of proximity, $F(1,27)=0.16, p=.69, \eta^{2} p$ $=.006$. There was no difference between the effects of expectancy and proximity, $F(1,27)=$ $0.52, p=.48 ., \eta_{p}^{2}=.019($ see Table 2$)$.

The pattern for anger was more complicated. There was no effect of trial type, $F(2,27)=$ $0.22, p=.81, \eta_{p}^{2}=.016$, nor of trial distribution, $F(1,28)=0.66, p=.41, \eta^{2}{ }_{p}=.023$, but there was a marginally significant interaction between trial type and trial distribution, $F(2,27)=3.27$, $p=.054, \eta_{p}^{2}=.20$. In the $36-\mathrm{AAB} / 72-\mathrm{ABC}$ condition there was a marginal effect of trial type, $F(2,13)=3.76, p=.051, \eta_{p}^{2}=.37$. The effect of expectancy was also marginally significant: Participants felt more anger on unexpected proximal or AAB trials $(M=2.33, S D=1.23)$ than on expected proximal or ABA trials $(M=2.00, S D=1.07), F(1,14)=4.38, p=.055, \eta^{2}{ }_{p}=.24$. The effect of proximity was significant but in the other direction than we expected: Participants felt less anger when the loss was proximal to a win (i.e., on expected proximal or ABA trials; $M$ $=2.00, S D=1.07$ ) than when the loss was distal to a win (i.e., on expected distal or ABC trials; $M=2.27, S D=1.10), F(1,14)=5.09, p=.041, \eta_{p}^{2}=.27$. The effect of proximity differed significantly from the effect of expectancy, $F(1,14)=7.88, p=.014, \eta_{p}^{2}=.36$. In the 72 $\mathrm{AAB} / 36-\mathrm{ABC}$ condition, there was no effect of trial type, $F(2,13)=1.23, p=.33, \eta^{2}{ }_{p}=.16$. There was no effect of expectancy: Participants were equally angry on unexpected proximal or AAB trials $(M=1.73, S D=0.88)$ and on expected proximal or ABA trials $(M=2.07, S D=$ 1.03), $F(1,14)=2.50, p=.14, \eta^{2} p=.15$. There was also no effect of proximity: Participants were 
equally angry on expected proximal or ABA trials $(M=2.07, S D=1.03)$ and on expected distal or ABC trials $(M=1.93, S D=0.96), F(1,14)=0.48, p=.50, \eta^{2}{ }_{p}=.033$.

Contrary to the high correlations in Experiment 1, there were no correlations between the effects of expectancy on anger, disappointment, and frustration (see Table 3). For proximity, the only correlation that reached significance was a negative correlation between the effect of proximity on anger and the effect of proximity on frustration. Confirming the pattern of Experiment 1, few significant correlations were observed between the effects of expectancy and proximity on the tendency to repair, on the one hand, and the effects of expectancy and proximity on negative feelings, on the other hand. Exceptions were (a) a marginal negative relation between the effects of expectancy/proximity on disappointment and the effects of expectancy/proximity on the amount of betted credits, and (b) a significant positive relation between the effect of expectancy on the self-reported tendency to choose a second chance and the effect of expectancy on disappointment.

\section{Discussion}

Most of the findings of Experiment 1 were confirmed across the two new trial distributions introduced in Experiment 2. Trial distribution did not interact with any of the effects of expectancy and proximity on the dependent measures, except when angry feelings were considered. Trial distribution did have a global motivational effect, however. Participants in the condition with the least (36) unexpected proximal loss or AAB trials and the most (72) expected distal loss or $\mathrm{ABC}$ trials were more inclined to repair the goal-incongruent outcomes than participants in the condition with the most (72) unexpected proximal loss or AAB trials and the least (36) expected distal loss or ABC trials. This data pattern confirms previous findings that 
participants especially persist in gambling in face of moderate (instead of high) amounts of nearmisses (Kassinove \& Schare, 2001).

Most importantly, the majority of the findings of Experiment 1 were replicated in Experiment 2, which confirms that these findings were robust across variations in trial distribution. We again observed that both expectancy and proximity influenced the tendency to repair as measured by behavior (i.e., to choose a second chance) and self-reports. We also replicated the result that unexpected losses led to more disappointment than expected losses, but that feelings of disappointment were unaffected by the appraisal of proximity. Different from Experiment 1, however, this result did not replicate for feelings of anger and frustration. The effect of expectancy on anger seemed to be dependent on the specific distribution of the trials: Feelings of anger were marginally increased on $\mathrm{AAB}$ trials compared to $\mathrm{ABA}$ trials for participants who received a low amount of AAB trials and a high amount of ABC trials (the 36$\mathrm{AAB} / 72-\mathrm{ABC}$ condition) but not for participants who received a high amount of $\mathrm{AAB}$ trials and a low amount of $\mathrm{ABC}$ trials (the 72-AAB/36-ABC condition). It may be noted that participants' expectation of winning ten cents on AA trials was equally high in both conditions. A possible explanation for this pattern of findings is that when expectations are frequently disconfirmed (in the 72-AAB/36-ABC condition), feelings of anger following unexpected events are attenuated.

In Experiment 3, we further examined the effects of expectancy and proximity on feelings of disappointment, frustration, and anger. Experiments 1 and 2 suggested that the feeling component was influenced only by the appraisal of expectancy, whereas the motivational component (i.e., the tendency to repair) was influenced by both the appraisals of expectancy and of proximity. Importantly, however, the feeling component was measured retrospectively whereas the motivational component was measured both retrospectively and trial by trial. The 
observed differences between the feeling and motivational component thus could be an artifact of our measurement method. In Experiment 3, we investigated whether the observation that negative feelings are influenced by the appraisal of expectancy and not by the appraisal of proximity would replicate using a trial-by-trial assessment of feelings ${ }^{1}$.

\section{Experiment 3}

\section{Method}

Participants.

Thirty-four participants $\left(M_{\text {age }}=23,6\right.$ men) took part in the study in return for payment (10€, augmented with the amount they won in the game). Twenty-nine participants were students of which fourteen studied psychology; two participants were phd students of Ghent University (both faculty of medicine and health sciences), and three participants were employed elsewhere.

\section{Procedure.}

The procedure was similar to the procedure of Experiment 1 (using the same design with a balanced number of $\mathrm{AAB}, \mathrm{ABA} / \mathrm{ABB}$, and $\mathrm{ABC}$ trials) with the following changes. First, we instructed participants that on some trials we would measure their feelings with regard to the slot machine outcome. We also demonstrated the nature of measurement before the start of the experiment. On a subset of trials, $2000 \mathrm{~ms}$ after a goal-incongruent outcome (0 cent) was presented, a visual analog scale appeared below the slot machine, ranging from not at all to yes completely, together with one of the following labels: the Dutch words for disappointment (teleurstelling), frustration (frustratie), and anger (kwaadheid). Participants were asked to indicate the degree to which they experienced these feelings by clicking at a position on the scale and pressing ENTER. After the participant had responded, the second chance and pass buttons 
appeared. The data from the visual analog scale ranged from 0 to 100 . Second, participants could choose for a second chance or pass using two keys of the keyboard (respectively 7 and 9) instead of using the mouse-shaped response box (Voss, et al., 2007). This was done to avoid confusion with the mouse responses used to collect online self-reported feelings in this experiment.

Third, we reduced the total number of credits that participants could bet throughout the game. This allowed us to measure feelings of disappointment, frustration, and anger in exactly the same circumstances on $\mathrm{AAB}, \mathrm{ABA} / \mathrm{ABB}$, and $\mathrm{ABC}$ trials. Experiments 1 and 2 suggested that participants' tendency to repair goal-incongruent outcomes was stronger on AAB trials than on $\mathrm{ABA} / \mathrm{ABB}$ trials and stronger on $\mathrm{ABA} / \mathrm{ABB}$ trials than on $\mathrm{ABC}$ trials. Hence, if we would obtain differences in feelings between the different trial types, it could be a direct effect of expectancy and proximity, but also of anticipating or not anticipating a repair action (e.g., negative feelings may be attenuated when anticipating a repair action). By reducing the number of credits to a hundred, we reduced the number of trials in which a repair action was possible. With a total of a hundred credits, participants could place five bets with twenty credits, which was the average bet in Experiments 1 and 2, or a maximum of ten bets with ten credits (which was the minimum bet). Hence, we anticipated that we would obtain a sufficient number of AAB trials, $\mathrm{ABA} / \mathrm{ABB}$ trials, and $\mathrm{ABC}$ trials on which participants did not repair and therefore did not anticipate a repair action. This enabled us to eliminate any impact of the anticipation of a repair action by conducting all analyses on the set of $\mathrm{AAB}, \mathrm{ABA} / \mathrm{ABB}$, and $\mathrm{ABC}$ trials on which participants did not anticipate a repair action.

Fourth, we took a number of additional measures to keep participants motivated to play the game despite the reduction in repair opportunities. First, to compensate for the decrease in profit due to the reduced repair opportunity, we rewarded participants with 20 cents instead of 10 
cents. Second, we reduced the total number of trials from three blocks of 51 trials to one block of 51 trials, with ten measurement trials for each feeling (disappointment, frustration and anger): three $\mathrm{AAB}$ trials, three $\mathrm{ABC}$ trials, and four $\mathrm{ABA} / \mathrm{ABB}$ trials (two $\mathrm{ABA}$ and two $\mathrm{ABB}$ trials). In Experiments 1 and 2, the tendency to repair was repeatedly measured on a large number (144) of goal-incongruent trials, because we anticipated that complex strategies and changes in those strategies may cause noise that may overshadow the effects of expectancy and proximity. However, such a high number of trials on which the game is interrupted for the assessment of feelings results in a very lengthy procedure that is likely to be very tedious. Hence we decided to reduce the number of trials.

\section{Results}

The analyses were similar to the analyses of Experiment 1 with two exceptions. First, in Experiments 1 and 2 there was one (retrospective) data point for each combination of feeling (disappointment, frustration, and anger) and trial type (AAB, $\mathrm{ABA} / \mathrm{ABB}$, and $\mathrm{ABC})$. In Experiment 3, we collected multiple (online) data points for feelings of disappointment, frustration, and anger on the different trial types. Hence these data points were first averaged across feeling (disappointment, frustration, and anger) and trial type (AAB, $\mathrm{ABA} / \mathrm{ABB}$, and ABC) before they were entered in the repeated measures MANOVA's. Second, the trial-by-trial assessment of feelings allowed us to control for a potential confounding factor, anticipation of a repair action, by performing two analyses for each dependent variable: one analysis including all trials (also those on which participants repaired after rating their feelings) and one analysis excluding trials on which participants repaired after rating their feelings (12.65\% of the trials). Despite the restricted possibility to repair goal-incongruent outcomes in Experiment 3, trial type did influence whether participants took a second chance, $F(2,32)=4.67, p=.017, \eta^{2}{ }_{p}=.23$ (but 
not the number of betted credits, $F<1 ; M_{A A B}=16.91, S D=5.21 ; M_{A B A / A B B}=17.27, S D=5.11$; $\left.M_{A B C}=17.35, S D=5.40\right)$. The effect of expectancy on taking a second chance failed to reach significance, $F(1,33)=1.06, p=.55, \eta^{2} p=.017$. Participants took a second chance equally often on unexpected proximal or AAB trials $(M=13.42 \%, S D=6.55)$ and on expected proximal or ABA/ABB trials $(M=12.32 \%, S D=6.96)$. However, the effect of proximity again reached significance, $F(1,33)=16.94, p=.008, \eta_{p}^{2}=.19$, suggesting that participants more often took a second chance on expected proximal or ABA/ABB trials $(M=12.32 \%, S D=6.96)$ than on expected distal or ABC trials $(M=7.90 \%, S D=6.40)$. Thus, in Experiments 1 and 2 we found both an influence of proximity and expectancy on the tendency to repair, but in Experiment 3, in which the opportunity to repair was severely restricted, we only found an effect of proximity on the tendency to repair.

The results of all analyses are presented in Table 4. This table shows that the difference between the analyses on the full trial set (including repair trials) vs. the trimmed trial set (excluding repair trials) was negligible. Hence, we will only describe the results of the trimmed analyses in the text and refer the reader to Table 4 for the results of the full analyses.

For feelings of disappointment, we obtained a strong effect of trial type, $F(2,32)=9.89$, $p<.001, \eta^{2}{ }^{2}=.38$. The effect of expectancy was significant (i.e., participants felt more disappointment on unexpected proximal or $\mathrm{AAB}$ trials than on expected proximal or $\mathrm{ABA} / \mathrm{ABB}$ trials), $F(1,33)=20.38, p<.001, \eta_{p}^{2}=.38$. The effect of proximity failed to reach significance, $F(1,33)=0.12, p=.73, \eta_{p}^{2}=.004$. The effect of expectancy was significantly stronger than the effect of proximity, $F(1,33)=10.96, p=.002, \eta^{2}{ }^{2}=.25$.

For feelings of frustration, we obtained a significant effect of trial type, $F(2,32)=4.24, p$ $=.023, \eta^{2}{ }^{2}=.21$. The effect of expectancy was significant (i.e., participants felt more frustration 
on unexpected proximal or $\mathrm{AAB}$ trials than on expected proximal or $\mathrm{ABA} / \mathrm{ABB}$ trials $), F(1,33)$ $=8.45, p=.006, \eta_{p}^{2}=.20$. The effect of proximity failed to reach significance, $F(1,33)=0.29, p$ $=.60, \eta_{p}^{2}=.009$. The effect of expectancy was not significantly stronger than the effect of proximity, $F(1,33)=2.29, p=.14, \eta_{p}^{2}=.065$.

For feelings of anger, we obtained a significant effect of trial type, $F(2,32)=4.46, p=$ $.020, \eta_{p}^{2}=.22$. As can be seen in Table 4 , the effect of expectancy was significant (i.e., participants felt more anger on unexpected proximal or AAB trials than on expected proximal or ABA/ABB trials), $F(1,33)=9.17, p=.005, \eta_{p}^{2}=.22$. The effect of proximity failed to reach significance, $F(1,33)=0.10, p=.75, \eta_{p}^{2}=.003$. The effect of expectancy was significantly stronger than the effect of proximity, $F(1,33)=4.80, p=.036, \eta^{2}{ }_{p}=.13$.

We calculated the correlations between the effects of expectancy on the different negative feelings as well as the effects of proximity on the different negative feelings. The effects of expectancy on disappointment, frustration, and anger were unrelated, except for two marginally positive correlations between anger and disappointment and anger and frustration that failed to generalize across trial set (full vs. trimmed). Contrary to the effects of expectancy, the effects of proximity on disappointment, frustration, and anger were interrelated (see Table 4).

\section{Discussion}

Experiment 3 provides further support for the conclusion that feelings of disappointment, frustration, and anger are unaffected by the appraisal of proximity but are significantly influenced by the appraisal of expectancy. More in particular, we again observed that unexpected goal-incongruent events elicited stronger feelings of disappointment, frustration, and anger than expected goal-incongruent events. We discarded the alternative hypothesis that a confounding factor (the anticipation of a repair action) explained the differences between the trial types by 
conducting our analyses on a trial set that was limited to those trials in which participants did not repair (and hence did not anticipate a repair action). It may be noted that the effect size of the effect of expectancy on feelings of disappointment was much larger than of the effect of expectancy on feelings of frustration and anger, and that this difference was more pronounced in the trial-by-trial assessment of feelings of Experiment 3 than in the retrospective assessment of Experiment 1. In addition, we observed that despite the severe restriction on the number of times participants could repair (i.e., on average, participants repaired on five trials during the entire experiment), proximity still had a significant influence on repair behavior. Thus, Experiment 3 again suggested that both the appraisals of expectancy and proximity play a distinct role in emotion elicitation.

\section{General Discussion}

Previous research suggested that goal-incongruent events hit harder when they are unexpected and when the goal was just missed than when they are expected and the goal was missed by far. In this research, however, expectancy and proximity often were confounded. The aim of the present studies was to investigate whether emotions are separately enhanced by the appraisals of expectancy and proximity or whether only one of the two variables determines the emotional response. We manipulated expectancy and proximity in a gambling experiment and measured emotions via changes in action tendencies (the tendency to repair) and negative feelings (disappointment, frustration, and anger).

Our studies suggest that expectancy and proximity each have a separate influence on emotions. Expectancy affected both the motivational and the feeling component of the emotion: Unexpected losses increased the motivation to repair a goal-incongruent event and intensified feelings of disappointment (all experiments) as well as feelings of frustration and anger 
(Experiment 1 and 3) compared to expected losses. Our data thus support the idea that expecting to attain a goal generally amplifies negative affect when that goal is not attained. Proximity, on the other hand, affected the motivational component of the emotion only. When a goalcongruent outcome was just missed, participants' motivation to repair a goal-incongruent event was stronger than when a goal-congruent outcome was missed by far. Proximity did not affect feelings of disappointment, frustration, and anger.

The finding that expectancy influenced both the motivational and the feeling component of the emotion whereas proximity influenced the motivational component only is compatible with emotion theories that emphasize the importance of the appraisal of expectancy (Reisenzein, 2009; Roseman, 2011). Importantly, our manipulation checks and motivational data excluded the possibility that the proximity information was simply ignored (i.e., that on trials that were used to calculate the effect of proximity, i.e., ABA/ABB vs. ABC trials, participants ignored the crucial third symbol). Construal level theory (Trope \& Liberman, 2010) might explain this pattern of findings via a differential impact of expectancy and proximity on the psychological distance to a win. Psychological distance is assumed to be influenced by the probability of a win: As the probability of a win increases, the psychological distance to a win decreases (Trope \& Liberman, 2010). The probability of a win is estimated as high vs. low (a) prospectively (before the loss) in the case of an unexpected vs. expected loss, and (b) retrospectively (after the loss) in the case of a proximal vs. distal loss. It could be that the psychological distance is more strongly affected by the probability of a win when it is estimated prospectively rather than retrospectively.

The present findings can be relevant for the literature on emotion regulation. At first sight, lowering one's expectations seems beneficial to reduce feelings of disappointment (and perhaps also frustration and anger) when obtaining a goal-incongruent outcome. Our studies 
reveal, however, that such a regulation strategy could have a detrimental effect on the motivation to repair a goal-incongruent outcome. To the extent that repairing is possible and functional, this is a negative side effect. Our studies furthermore suggest that changes in the appraisal of proximity do not influence negative feelings but do change the tendency to repair. Thus, reappraising a loss as less proximal to a win may not be the most effective strategy to regulate feelings of disappointment, frustration, and anger.

Future research could address a number of potential boundary conditions of the present findings. More specifically, our results may be bound to the use of a specific sample, a specific experimental context, or a specific measurement method of the tendency to repair. First, with regard to the specific sample, participants of Experiments 1 and 2 reported having a moderate to high experience with gambling. Past research has suggested that experienced gamblers may be more sensitive to the effects of near-misses (Habib \& Dixon, 2010, but see Reid, 1986). The role of proximity was thus possibly overestimated in our studies. A replication with participants that are less experienced with gambling would solve this issue.

Second, our results could be bound to the specific context of the slot machine game or to the context of gambling in general. For instance, in our experiments, the goal-incongruent events were caused by an external, non-living agent. The effects of expectancy and proximity may turn out to be different when the goal-incongruent events are caused by the self. It may be noted that in other, more naturalistic, settings it may be difficult to disentangle the influence of proximity and expectancy from each other and from other (appraisal) variables such as coping potential and agency. For instance, when a student receives a grade that is incongruent with his/her desired grade, the appraisal that the actual grade is close to the desired grade may often go together with the appraisal of high coping potential (i.e., the student may believe that he/she can obtain the 
desired grade next time). Moreover, when the student had a high expectation to obtain the desired grade, he/she may be more likely to attribute the cause of (unexpectedly) not obtaining this grade externally (e.g., to an unfair grading method or professor) rather than internally (i.e., to the self). One other important contextual factor may be the amount of expected/unexpected and proximal/distal goal-incongruent trials. Although Experiment 2 partly addressed this issue, some questions remain unanswered, such as whether the findings of Experiment 3 would replicate across different trial frequencies and whether the same findings would be obtained in a single trial experiment.

Third, there was a relatively high degree of coherence between the tendency to repair as measured via behavior and as measured via self-reports. This could be attributed to the fact that participants had the opportunity to reflect on their behavior in the game. In future studies, researchers could investigate the effects of expectancy and proximity on repair behavior that is measured under conditions that reduce this opportunity, such as time pressure and/or a secondary task that has to be completed. In this way, we could investigate whether our results generalize to automatically activated repair tendencies that are less easy to report.

Our studies have other limitations that might be addressed in future research. First, the design of the current studies only allowed to investigate (a) the effect of expectancy within a context of high proximity and (b) the effect of proximity within a context of expected losses. Future studies may aim for a more complete design that includes unexpected distal loss trials so that one can examine the influence of each variable given all values of the other variable as well as the interaction between expectancy and proximity. There may be ways to induce unexpectedness without also inducing high proximity. For instance, unexpectedness could be induced by providing participants with information on the probability of a win before the start of 
a trial, instead of letting them infer this from the repetition of the same symbol in AA trials. Both expected and unexpected losses can then be combined with the information that a win almost happened (i.e., proximal loss) or not (i.e., distal loss). Such an experiment would mimic unexpected but distal losses in real life. For example, a tennis player may have a high expectation of winning before the match but eventually lose the match (unexpectedly) with an extremely low score. It remains an empirical question whether in cases like this there is actual independence of expectancy and proximity or whether one variable has a systematic influence on the other.

Another objection may be that the obtained differences in the tendency to repair do not reflect "emotional" action tendencies, but elaborated strategies to maximize one's chances at winning. Deciding whether a particular action tendency or behavior is part of an emotional episode or not depends on one's definition of emotions or emotional episodes. Some would argue that positive and negative feelings are a defining property of emotions (Ortony \& Turner, 1990) and that emotional behavior is behavior that is accompanied by positive and negative feelings (e.g., the affect-as-information model; Clore, 1994; Ketelaar \& Au, 2003; Schwarz \& Clore, 1983). According to this view, one might argue that the effect of expectancy on the tendency to repair was more "emotional" than the effect of proximity, because on unexpected loss trials the feelings of disappointment, frustration and anger exceeded a threshold that could lead one to decide that these feelings were present (e.g., received an average rating of at least 3 on a 7-point scale ranging from not at all to yes completely in Experiment 1 or an average rating of at least 25 on the visual analog scale in Experiment 3).

Others have defined emotions as states that tilt behavior towards irrationality (but see Damasio, 1994; Frank, 1988; Lazarus, 1995). This idea is especially popular in folk psychology 
(Parrott, 1995) and has some adherents in the scientific world. For instance, some researchers propose that emotions were adaptive for our ancestors but give rise to suboptimal or irrational choices in the modern world (Haselton \& Ketelaar, 2006; Sripada \& Stich, 2004) and that emotional behavior typically relies on heuristics rather than on accurate cost-benefit analyses (Quartz, 2009). Repair behavior can be considered as rational or as stemming from a cost-benefit analysis when it is more frequent on trials on which the participant believes that repairing will be relatively easy (i.e., coping potential is high) than on trials on which the participant believes that repairing will be relatively difficult (i.e., coping potential is low). In this respect, the influence of expectancy on repair behavior could be considered more rational and less "emotional" than the influence of proximity, because expectancy was related to coping potential (participants rated their coping potential as higher on unexpected proximal loss trials than on expected proximal loss trials), whereas proximity was not (participants rated their coping potential as equal on expected proximal loss trials than on expected distal loss trials).

Still other emotion researchers (Scherer, 2009) suggest that emotional episodes are characterized by a high degree of synchronization between the components (cognitive, motivational, somatic, motor, and feeling). One could thus argue that the lack of significant correlations between feelings and the tendency to repair suggests that neither the effects of expectancy nor proximity are truly emotional. There are, however, several reasons not to attach too much weight to the correlations obtained in our studies (e.g., our small sample sizes and the presence of experimental manipulations which tend to push participants in the same direction and remove the interindividual variation that is necessary to obtain correlations). Future studies may investigate the presence of other criteria that have been proposed to disentangle emotional from non-emotional episodes, such as characteristic facial expressions (Ekman, 1994) or the 
extent to which the action tendency takes priority over other goals (i.e., control precedence, Frijda, 1986). It may finally be noted that some authors argue that there are no objective criteria that separate emotional from non-emotional episodes (Russell, 2009). Even without consensus on how to classify an episode as emotional or not, studying the influence of appraisal on action tendencies remains valuable in its own right.

To conclude, there is an old Taoist saying that "loss is not as bad as wanting more." Our studies are the first to show that the unexpectedness of the outcome as well as the thought that a better outcome was within reach independently increase the motivation to obtain that outcome. Disconfirmed expectations, moreover, increased feelings of disappointment, frustration, and anger. 


\section{References}

Amsel, A. (1958). The role of frustrative nonreward in noncontinuous reward situations. Psychological Bulletin, 55, 102-119. doi:10.1037/h0043125

Ariyabuddhiphongs, V., \& Phengphol, V. (2008). Near miss, gambler's fallacy and entrapment: Their influence on lottery gamblers in thailand. Journal of Gambling Studies, 24, 295305. doi:10.1007/s10899-008-9098-4

Arnold, M. B. (1960). Emotion and personality: Psychological aspects. New York: Columbia University Press.

Barrett, L. F. (1997). The relationships among momentary emotion experiences, personality descriptions, and retrospective ratings of emotion. Personality and Social Psychology Bulletin, 23, 1100-1110. doi:10.1177/01461672972310010

Clark, L., Crooks, B., Clarke, R., Aitken, M. R. F., \& Dunn, B. D. (2012). Physiological responses to near-miss outcomes and personal control during simulated gambling. Journal of Gambling Studies, 28, 123-137. doi:10.1007/s10899-011-9247-z

Clark, L., Lawrence, A. J., Astley-Jones, F., \& Gray, N. (2009). Gambling near-misses enhance motivation to gamble and recruit win-related brain circuitry. Neuron, 61, 481-490. doi:10.1016/j.neuron.2008.12.031

Clore, G. L. (1994). Why emotions are felt. In P. Ekman \& R. J. Davidson (Eds.), The nature of emotion: Fundamental questions (pp. 103-111): New York: Oxford University Press.

Côté, D., Caron, A., Aubert, J., Desrochers, V., \& Ladouceur, R. (2003). Near wins prolong gambling on a video lottery terminal. Journal of Gambling Studies, 19, 433-438. doi:10.1023/a:1026384011003

Damasio, A. R. (1994). Descartes' error : Emotion, reason, and the human brain. New York: Putnam.

Dixon, M. R., \& Schreiber, J. E. (2004). Near-miss effects on response latencies and win estimations of slot machine players. Psychological Record, 54, 335-348.

Ekman, P. (1994). Moods emotions and traits. In P. Ekman \& R. Davidson (Eds.), The nature of emotion: Fundamental questions. (pp. 15-19): New York: Oxford University Press.

Endsley, R. C. (1966). Effortfulness and blocking at different distances from goal as determinants of response speed and amplitude. Journal of Experimental Child Psychology, 3, 18-30. doi:10.1016/0022-0965(66)90058-0

Feather, N. T., \& Simon, J. G. (1971). Attribution of responsibility and valence of outcome in relation to initial confidence and success and failure of self and other. Journal of Personality and Social Psychology, 18, 173-188. doi:10.1037/h0030845

Fraisse, P. (1964). The sources of emotion. In J. Cohen (Ed.), Readings in psychology (pp. 302324): London: Allen \& Unwin.

Frank, R. H. (1988). Passions within reason: The strategic role of the emotions (1st ed.). New York: Norton.

Frijda, N. H. (1986). The emotions: Cambridge: Cambridge University Press.

Frijda, N. H., Kuipers, P., \& ter Schure, E. (1989). Relations among emotion, appraisal, and emotional action readiness. Journal of Personality and Social Psychology, 57, 212-228. doi:10.1037//0022-3514.57.2.212

Golub, S. A., Gilbert, D. T., \& Wilson, T. D. (2009). Anticipating one's troubles: The costs and benefits of negative expectations. Emotion, 9, 277-281. doi:10.1037/a0014716 
Grandjean, D., Sander, D., \& Scherer, K. R. (2008). Conscious emotional experience emerges as a function of multilevel, appraisal-driven response synchronization. Consciousness and Cognition, 17, 484-495. doi:10.1016/j.concog.2008.03.019

Habib, R., \& Dixon, M. R. (2010). Neurobehavioral evidence for the "Near-miss" Effect in pathological gamblers. Journal of the Experimental Analysis of Behavior, 93, 313-328. doi:10.1901/jeab.2010.93-313

Haner, C. F., \& Brown, P. A. (1955). Clarification of the instigation to action concept in the frustration-aggression hypothesis. The Journal of Abnormal and Social Psychology, 51, 204-206. doi:10.1037/h0044818

Haselton, M. G., \& Ketelaar, T. (2006). Irrational emotions or emotional wisdom? The evolutionary psychology of emotions and behavior. In J. P. Forgas (Ed.), Hearts and minds: Affective influences on social cognition and behavior (pp. 21-40): New York: Psychology Press.

Judd, C. M., Kenny, D. A., \& McClelland, G. H. (2001). Estimating and testing mediation and moderation in within-subject designs. Psychological Methods, 6, 115-134. doi:10.1037//1082-989x.6.2.115

Junge, M., Loureiro, d. A., V. , \& Reisenzein, R. (2010, October). The near miss effect: Counterfactual thinking or disconfirmation of expectancies? Paper presented at the 10th KogWis meeting of the German Society for Cognitive Science, Potsdam.

Kahneman, D., \& Miller, D. T. (1986). Norm theory: Comparing reality to its alternatives. Psychological Review, 93, 136-153. doi:Doi 10.1037//0033-295x.93.2.136

Kahneman, D., \& Tversky, A. (1982). The simulation heuristic. In D. Kahneman, P. Slovic \& A. Tversky (Eds.), Judgment under uncertainty: Heuristics and biases (pp. 201-208): New York: Cambridge University Press.

Kahneman, D., \& Varey, C. A. (1990). Propensities and counterfactuals: The loser that almost won. Journal of Personality and Social Psychology, 59, 1101-1110. doi:10.1037//00223514.59.6.1101

Kassinove, J. I., \& Schare, M. L. (2001). Effects of the "Near miss" And the "Big win" On persistence at slot machine gambling. Psychology of Addictive Behaviors, 15, 155-158. doi:10.1037/0893-164x.15.2.155

Ketelaar, T., \& Au, W. T. (2003). The effects of feelings of guilt on the behaviour of uncooperative individuals in repeated social bargaining games: An affect-as-information interpretation of the role of emotion in social interaction. Cognition and Emotion, 17, 429-453. doi:10.1080/02699930143000662

Lazarus, R. S. (1991). Emotion and adaptation. New York: Oxford University Press.

Lazarus, R. S. (1995). Vexing research problems inherent in cognitive-mediational theories of emotion and some solutions. Psychological Inquiry, 6, 183-196. doi:10.1207/s15327965pli0603_1

Luo, Q. L., Wang, Y., \& Qu, C. (2011). The near-miss effect in slot-machine gambling: Modulation of feedback-related negativity by subjective value. Neuroreport, 22, 989-993. doi:10.1097/Wnr.0b013e32834da8ae

Markman, K. D., McMullen, M. N., \& Elizaga, R. A. (2008). Counterfactual thinking, persistence, and performance: A test of the reflection and evaluation model. Journal of Experimental Social Psychology, 44, 421-428. doi:10.1016/j.jesp.2007.01.001 
Marshall, M. A., \& Brown, J. D. (2006). Emotional reactions to achievement outcomes: Is it really best to expect the worst? Cognition \& Emotion, 20, 43-63.

doi:10.1080/02699930500215116

McGraw, A. P., Mellers, B. A., \& Ritov, I. (2004). The affective costs of overconfidence. Journal of Behavioral Decision Making, 17, 281-295. doi:10.1002/bdm.472

McGraw, A. P., Mellers, B. A., \& Tetlock, P. E. (2005). Expectations and emotions of olympic athletes. Journal of Experimental Social Psychology, 41, 438-446. doi:10.1016/j.jesp.2004.09.001

Medvec, V. H., \& Savitsky, K. (1997). When doing better means feeling worse: The effects of categorical cutoff points on counterfactual thinking and satisfaction. Journal of Personality and Social Psychology, 72, 1284-1296. doi:10.1037/0022-3514.72.6.1284

Mellers, B. A., Schwartz, A., Ho, K., \& Ritov, I. (1997). Decision affect theory: Emotional reactions to the outcomes of risky options. Psychological Science, 8, 423-429. doi:10.1111/j.1467-9280.1997.tb00455.x

Moors, A. (2009). Theories of emotion causation: A review. Cognition and Emotion, 23, 625662. doi:10.1080/02699930802645739

Ortony, A., \& Turner, T. J. (1990). What's basic about basic emotions. Psychological Review, 97, 315-331. doi:10.1037//0033-295X.97.3.315

Parrott, W. G. (1995). But emotions are sometimes irrational. Psychological Inquiry, 6, 230-232.

Pederson, D. R., \& Mcewan, R. C. (1970). Children's reactions to failure as a function of instructions and goal distance. Journal of Experimental Child Psychology, 9, 51-58. doi:10.1016/0022-0965(70)90100-1

Qi, S. Q., Ding, C., Song, Y., \& Yang, D. (2011). Neural correlates of near-misses effect in gambling. Neuroscience Letters, 493, 80-85. doi:10.1016/j.neulet.2011.01.059

Quartz, S. R. (2009). Reason, emotion and decision-making: Risk and reward computation with feeling. Trends in Cognitive Sciences, 13, 209-215. doi:10.1016/j.tics.2009.02.003

Reid, R. L. (1986). The psychology of the near miss. Journal of Gambling Behavior, 2, 32-39. doi:10.1007/BF01019932

Reisenzein, R. (2009). Emotional experience in the computational belief-desire theory of emotion. Emotion Review, 1, 214-222. doi:Doi 10.1177/1754073909103589

Robinson, M. D., \& Clore, G. L. (2002). Belief and feeling: Evidence for an accessibility model of emotional self-report. Psychological Bulletin, 128, 934-960. doi:10.1037//00332909.128.6.934

Roseman, I. J. (2011). Emotional behaviors, emotivational goals, emotion strategies: Multiple levels of organization integrate variable and consistent responses. Emotion Review, 3, 434-443. doi:10.1177/1754073911410744

Roseman, I. J., Antoniou, A. A., \& Jose, P. E. (1996). Appraisal determinants of emotions: Constructing a more accurate and comprehensive theory. Cognition and Emotion, 10, 241-277. doi:10.1080/026999396380240

Russell, J. A. (2009). Emotion, core affect, and psychological construction. Cognition \& Emotion, 23, 1259-1283. doi:10.1080/02699930902809375

Ryan, T. J., \& Watson, P. (1968). Frustrative nonreward theory applied to childrens behavior. Psychological Bulletin, 69, 111-125. doi:10.1037/h0025312

Scherer, K. R. (1988). Criteria for emotion-antecedent appraisal: A review. In V. Hamilton, G. H. Bower \& N. H. Frijda (Eds.), Cognitive perspectives on emotion and motivation (pp. 89-126): Dordrecht, the Netherlands: Kluwer. 
Scherer, K. R. (1994). Emotion serves to decouple stimulus and response. In P. Ekman \& R. J. Davidson (Eds.), The nature of emotion: Fundamental questions (pp. 127-130): New York/Oxford: Oxford University Press.

Scherer, K. R. (2001). The nature and study of appraisal: A review of the issues. In K. R. Scherer, A. Schorr \& T. Johnstone (Eds.), Appraisal processes in emotion: Theory, methods, research (pp. 369-391): New York: Oxford University Press.

Scherer, K. R. (2005). What are emotions? And how can they be measured? Social Science Information Sur Les Sciences Sociales, 44, 695-729. doi:10.1177/0539018405058216

Scherer, K. R. (2009). The dynamic architecture of emotion: Evidence for the component process model. Cognition and Emotion, 23, 1307-1351. doi:10.1080/02699930902928969

Schwarz, N., \& Clore, G. L. (1983). Mood, misattribution, and judgments of well-being: Informative and directive functions of affective states. Journal of Personality and Social Psychology, 45, 513-523. doi:10.1037/0022-3514.45.3.513

Shepperd, J. A., \& McNulty, J. K. (2002). The affective consequences of expected and unexpected outcomes. Psychological Science, 13, 85-88. doi:10.1111/1467-9280.00416

Siemer, M., Mauss, I., \& Gross, J. J. (2007). Same situation - different emotions: How appraisals shape our emotions. Emotion, 7, 592-600. doi:10.1037/1528-3542.7.3.592

Skinner, B. F. (1953). Science and human behavior. New York: Macmillan.

Smith, C. A., \& Lazarus, R. S. (1990). Emotion and adaptation. In L. A. Pervin (Ed.), Handbook of personality theory and research (pp. 609-637): New York: Guilford.

Spruyt, A., Clarysse, J., Vansteenwegen, D., Baeyens, F., \& Hermans, D. (2010). Affect 4.0 a free software package for implementing psychological and psychophysiological experiments. Experimental Psychology, 57, 36-45. doi:10.1027/1618-3169/a000005

Sripada, C., \& Stich, C. (2004). Evolution, culture and the irrationality of the emotions. In D. Evans \& P. Cruse (Eds.), Emotion, evolution and rationality: New York: Oxford University Press.

Strickland, L. H., \& Grote, F. W. (1967). Temporal presentation of winning symbols and slotmachine playing. Journal of Experimental Psychology, 74, 10-13. doi:10.1037/h0024511

Sweeny, K., \& Shepperd, J. A. (2010). The costs of optimism and the benefits of pessimism. Emotion, 10, 750-753. doi:10.1037/a0019016

Trope, Y., \& Liberman, N. (2010). Construal-level theory of psychological distance. Psychological Review, 117, 440-463. doi:Doi 10.1037/A0018963

van Dijk, W. W., \& van der Pligt, J. (1997). The impact of probability and magnitude of outcome on disappointment and elation. Organizational Behavior and Human Decision Processes, 69, 277-284. doi:10.1006/obhd.1997.2688

Voss, A., Leonhart, R., \& Stahl, C. (2007). How to make your own response boxes: A step-bystep guide for the construction of reliable and inexpensive parallel-port response pads from computer mice. Behavior Research Methods, 39, 797-801. doi:10.3758/BF03192971 
Footnotes

1 We recently discovered that a subset of our findings were replicated by another research group that pursued a similar line of research and did employ a trial-by-trial assessment of feelings (Junge, Loureiro, \& Reisenzein, 2010, October). These researchers used a similar design to manipulate expectancy and proximity (i.e., slot-machine games) and asked participants to rate after each trial their disappointment about missed wins (their studies solely focused on feelings, so no action tendencies were measured). They also found that disappointment was influenced by the appraisal of expectancy but not by the appraisal of proximity. 
Table 1

Overview of the trial types, associated appraisal values, game outcomes, and distributions in Experiment 1 (Exp1) and Experiment 2 (Exp 2).

\begin{tabular}{|c|c|c|c|c|c|c|c|}
\hline \multirow{2}{*}{$\begin{array}{l}\text { Trial } \\
\text { Type }\end{array}$} & \multicolumn{3}{|c|}{ Appraisal } & \multirow{2}{*}{ Outcome } & \multirow{2}{*}{ Exp 1} & \multicolumn{2}{|c|}{$\operatorname{Exp} 2$} \\
\hline & & Expectancy & Proximity & & & 36-ABC/72-AAB & 72-ABC/36-AAB \\
\hline $\mathrm{ABC}$ & & Low & Low & 0 cent & 48 & 36 & 72 \\
\hline $\mathrm{ABA}$ & & Low & High & 0 cent & 24 & 18 & 18 \\
\hline $\mathrm{ABB}$ & & Low & High & 0 cent & 24 & 18 & 18 \\
\hline $\mathrm{AAB}$ & & High & High & 0 cent & 48 & 72 & 36 \\
\hline AAA & & High & - & 10 cent & 9 & 9 & 9 \\
\hline
\end{tabular}


Table 2

Overview of the results of Experiment 1 and 2. Columns labeled $A A B, A B A / A B B$, and $A B C$ contain means (SDs) of the dependent variables on each trial type; columns labeled expectancy and proximity present the seperate effects of expectancy and proximity (and the SDs of the effects); and columns labeled "Diff" presents the p-value of the difference tests between expectancy and proximity.

\begin{tabular}{|c|c|c|c|c|c|c|c|c|c|c|c|c|c|}
\hline & & \multicolumn{6}{|c|}{ Experiment 1} & \multicolumn{6}{|c|}{ Experiment 2} \\
\hline & & $A A B$ & $A B A / A B B$ & $A B C$ & Expectancy & Proximity & Diff & $A A B$ & $A B A / A B B$ & $A B C$ & Expectancy & Proximity & $\overline{\text { Diff }}$ \\
\hline \multirow{5}{*}{ Behavior } & $2^{\text {nd }}$ chance $(\%)$ & 46.68 (16.84) & $41.27(15.92)$ & $29.62(17.02)$ & $2.60(6.25)^{*}$ & $5.60(11.68)^{* *}$ & .17 & $50.32(19.35)$ & $44.72(15.31)$ & $28.47(15.88)$ & $5.60(16.42)^{(*)}$ & $16.25(20.39)^{* * *}$ & .029 \\
\hline & Bet & $22.41(5.85)$ & $21.79(6.06)$ & $21.64(5.81)$ & $0.63(2.02)^{(*)}$ & $0.15(2.73)$ & .51 & 21.07 (5.83) & $20.74(5.30)$ & 20.37 (4.48) & $0.34(2.18)$ & $0.37(4.57)$ & .98 \\
\hline & $S R 2^{\text {nd }}$ chance & $5.03(1.40)$ & $4.30(1.43)$ & 3.68 (1.73) & $0.73(1.73)^{*}$ & $0.62(2.00)^{(*)}$ & .83 & $4.90(1.32)$ & $4.47(1.25)$ & $3.60(1.87)$ & $0.43(1.10)^{*}$ & $0.87(1.96)^{*}$ & .31 \\
\hline & SR pass & $3.19(1.35)$ & $3.60(1.48)$ & $4.30(1.58)$ & $-0.41(1.66)$ & $-0.70(2.00)^{*}$ & .53 & $3.27(1.46)$ & $3.83(1.42)$ & $4.47(1.63)$ & $-0.57(1.59)^{*}$ & $-0.63(1.56)^{*}$ & .88 \\
\hline & SR bet & $25.24(9.40)$ & $22.76(11.15)$ & $20.87(11.10)$ & $2.49(6.33)^{*}$ & 1.89 (10.78) & .79 & $21.53(9.17)$ & $18.27(8.57)$ & 16.17 (11.69) & $3.27(10.29)^{(*)}$ & 2.10 (13.17) & .74 \\
\hline \multirow{3}{*}{ Feelings } & Disappointment & $3.38(1.89)$ & $2.46(1.54)$ & $2.35(1.55)$ & $0.92(1.23)^{* * *}$ & 0.11 & .016 & $3.47(1.57)$ & $2.77(1.44)$ & $2.70(1.53)$ & $0.70(0.99)^{* * * *}$ & $0.07(1.11)$ & .061 \\
\hline & Frustration & $2.92(1.77)$ & $2.24(1.62)$ & $2.03(1.57)$ & $0.68(1.23)^{* *}$ & $0.22(0.82)$ & .091 & $2.21(1.37)$ & $2.07(1.19)$ & $2.03(1.18)$ & $0.14(0.79)$ & $0.03(0.42)$ & .48 \\
\hline & Anger & $2.35(1.53)$ & $1.78(1.23)$ & $1.78(1.25)$ & $0.57(0.80)^{* * *}$ & $0.00(0.85)$ & .006 & $2.03(1.10)$ & $2.03(1.03)$ & $2.10(1.03)$ & $0.00(0.79)$ & $-0.07(0.64)$ & .75 \\
\hline
\end{tabular}

Note: ${ }^{(*)} p<.10, * p<.05, * * p<.01, * * * p<.001$. SR $=$ self-reported. 
Table 3

Table of correlations between the effects of expectancy as well as the effects of proximity on the different dependent variables: the tendency to repair as measured by the percentage of choosing for a second chance $\left(B H 2^{\text {nd }}\right)$, the average bet placed after choosing for a second chance (BH bet), the self-reported tendency to choose a second chance $\left(S R 2^{\text {nd }}\right)$, the self-reported tendency to pass (SR pass), the self-reported bet (SR bet), and feelings of disappointment, frustration, and anger (all self-reported).

\begin{tabular}{|c|c|c|c|c|c|c|c|c|c|c|c|c|c|c|}
\hline \multirow[b]{2}{*}{ EXPECTANCY } & \multicolumn{7}{|c|}{ Experiment 1} & \multicolumn{7}{|c|}{ Experiment 2} \\
\hline & (1) & (2) & (3) & (4) & (5) & (6) & (7) & (1) & (2) & (3) & (4) & (5) & (6) & (7) \\
\hline (1) $B H 2^{\text {nd }}$ & & & & & & & & & & & & & & \\
\hline (2) BH bet & -.10 & & & & & & & -12 & & & & & & \\
\hline (3) $S R 2^{\text {nd }}$ & .15 & -.21 & & & & & & $.60^{* * * *}$ & -.28 & & & & & \\
\hline (4) SR pass & -.13 & .19 & $-.75^{* * *}$ & & & & & $-.60^{* *}$ & .19 & $-.41^{*}$ & & & & \\
\hline (5) SR bet & .06 & .20 & .24 & $-.34^{*}$ & & & & .11 & -.17 & .15 & $-.51^{* *}$ & & & \\
\hline (6) Disappointment & .00 & -.16 & .20 & -.18 & .25 & & & -.16 & $-.36^{(*)}$ & .16 & .02 & -.04 & & \\
\hline (7) Frustration & -.06 & .04 & .25 & -.16 & .20 & $.66^{* * *}$ & & .29 & -.16 & $.38^{*}$ & -.28 & -.10 & .24 & \\
\hline (8) Anger & .18 & -.18 & .11 & -.14 & .16 & $.72^{* * *}$ & $.69^{*}$ & -.05 & -.05 & .12 & .25 & -.09 & .09 & .11 \\
\hline
\end{tabular}

PROXIMITY

(1) $B H 2^{\text {nd }}$

(2) $\mathrm{BH}$ bet $.26 \quad .02$

$\begin{array}{lllll}\text { (3) } S R 2^{\text {nd }} & .40^{*} & .22 & .21 & .41^{*}\end{array}$

(4) SR pass $\quad-.46^{* *}-.28 \quad-.78^{* * *} \quad-.32^{(*)} \quad-.26 \quad-.83^{* * *}$

(5) SR bet $\quad .33^{*} \quad .39^{*} \quad .67^{* * *} \quad-.67^{* * *} \quad 137^{*} \quad .39^{*} \quad .62^{* * *} \quad .70^{* * *}$

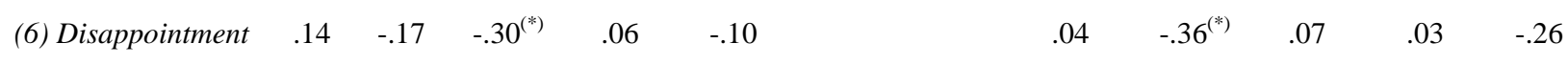

$\begin{array}{lllllllllllll}\text { (7) Frustration } & .10 & .02 & .10 & -.04 & .01 & .26 & .10 & .07 & .05 & -.02 & .02 & .15\end{array}$

$\begin{array}{lllllllllllllll}\text { (8) Anger } & .10 & .13 & -.03 & -.07 & -.02 & .39^{*} & .64^{* * *} & .00 & .13 & .02 & .13 & -.04 & -.28 & -.38^{*}\end{array}$

Note: ${ }^{(*)} p<.10, * p<.05, * * p<.01, * * * p<.001$ 
Table 4

Overview of the results of Experiment 3 with and without repair trials. Columns labeled $A A B, A B A / A B B$, and $A B C$ contain means $(S D s)$ of the dependent variables on each trial type; columns labeled expectancy and proximity present the separate effects of expectancy and proximity (and the SDs of the effects); columns labeled "Diff" presents the p-value of the difference tests between expectancy and proximity, columns labeled "CorExpectancy" and "CorProximity" present the correlations between the effects of expectancy as well as the effects of proximity on the different dependent variables.

CorExpectancy CorProximity

\begin{tabular}{|c|c|c|c|c|c|c|c|c|c|c|c|}
\hline & & $A A B$ & $A B A / A B B$ & $A B C$ & Expectancy & Proximity & Diff & (1) & (2) & (1) & (2) \\
\hline (1) Disappointment & incl. repair & $34.08(27.48)$ & $25.35(24.46)$ & $25.52(23.56)$ & $8.73(9.90)^{* * *}$ & $-0.17(10.16)$ & .002 & & & & \\
\hline \multirow{2}{*}{ (2) Frustration } & incl. repair & $29.58(27.18)$ & $26.20(25.79)$ & $24.09(23.43)$ & $3.38(9.18)^{*}$ & $2.11(9.66)$ & .60 & .00 & & $.52^{* *}$ & \\
\hline & excl. repair & $29.85(27.88)$ & $25.33(25.00)$ & $24.38(23.75)$ & $4.51(9.06)^{* *}$ & $0.95(10.32)$ & .14 & .13 & & $.38^{*}$ & \\
\hline \multirow{2}{*}{ (3) Anger } & incl. repair & $22.32(26.95)$ & 17.17 (19.57) & 16.87 (19.59) & $5.15(9.94)^{* *}$ & $0.30(8.92)$ & .033 & $.33^{(*)}$ & .20 & $.52^{* *}$ & $.30^{(*)}$ \\
\hline & excl. repair & $22.67(27.69)$ & $17.58(20.83)$ & $17.09(20.60)$ & $5.09(9.79)^{* *}$ & $0.49(9.01)$ & .036 & .12 & $.31^{(*)}$ & $.53^{* *}$ & .25 \\
\hline
\end{tabular}

Note: ${ }^{(*)} p<.10,{ }^{*} p<.05,{ }^{* *} p<.01,{ }^{* * *} p<.001$ 


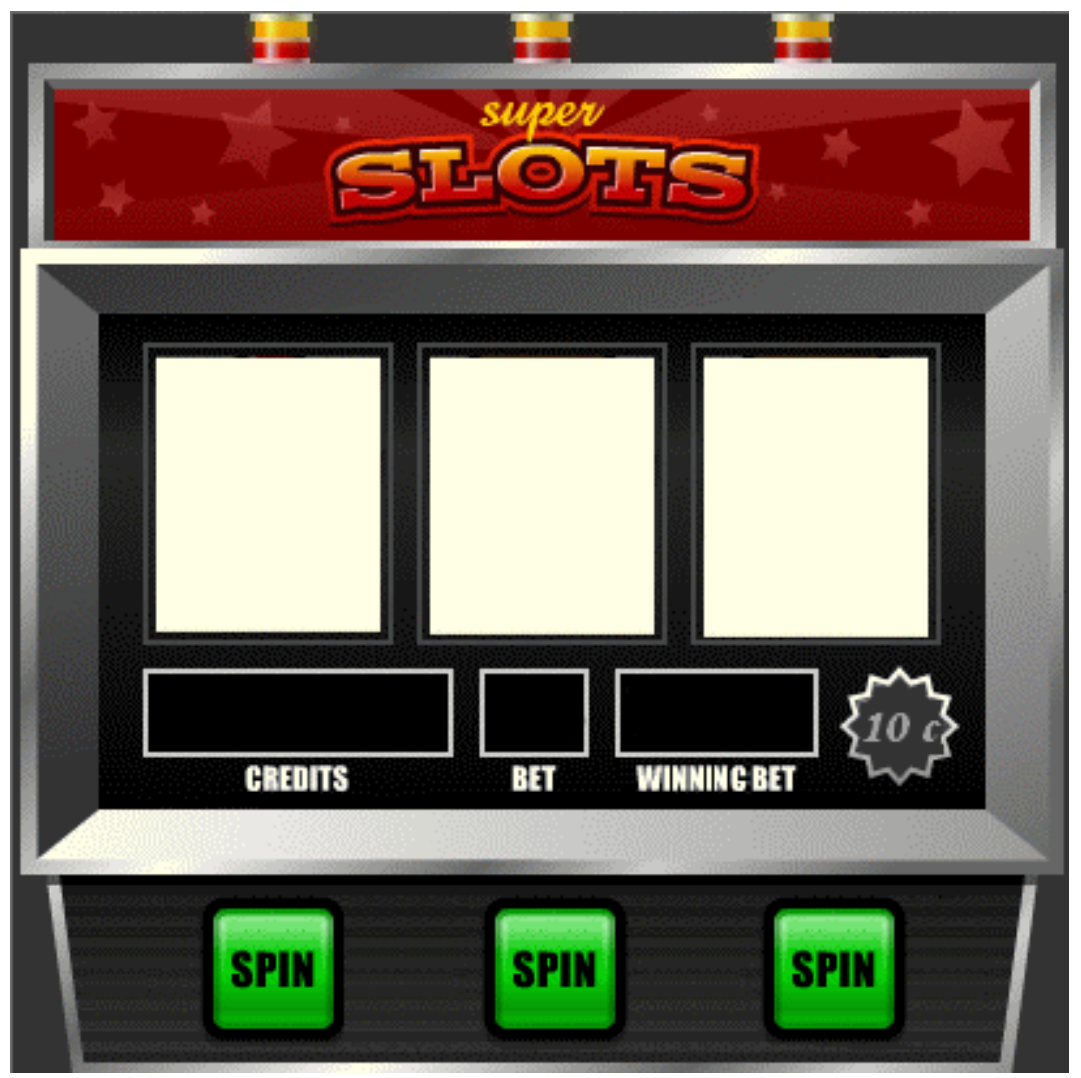

Figure 1. The slot machine with the three slots (upper part), the three information boxes (middle part), and the three spin buttons (lower part). 